\title{
A Dynamic Model of Lawsuit Joinder And SetTlement
}

\section{by}

Andrew F. Daughety and Jennifer F. Reinganum

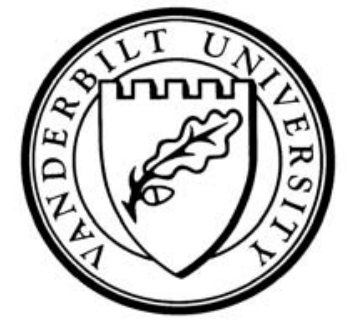

Working Paper No. 09-W11

September 2009

\section{DEPARTMENT OF ECONOMICS \\ VANDERBILT UNIVERSITY \\ NASHVILLE, TN 37235}

www.vanderbilt.edu/econ 


\title{
A Dynamic Model of Lawsuit Joinder and Settlement*
}

\author{
Andrew F. Daughety \\ Jennifer F. Reinganum \\ Department of Economics and Law School \\ Vanderbilt University \\ andrew.f.daughety@vanderbilt.edu \\ jennifer.f.reinganum@vanderbilt.edu
}

February 2009

Last Revised: July 2009

* Support from National Science Foundation grant SES08-14312 is gratefully acknowledged. We thank participants in the Summer Workshop in Industrial Organization 2009, University of Auckland, the Third Annual Triangle Law and Economics Conference, Duke University, PET-09, Galway, and seminar audiences at the Universitat Autònoma de Barcelona, and Universidad Carlos III de Madrid for comments on an earlier draft. 


\title{
A Dynamic Model of Lawsuit Joinder and Settlement Andrew F. Daughety and Jennifer F. Reinganum Vanderbilt University
}

\begin{abstract}
In this paper we examine a dynamic model of the process by which multiple related lawsuits may be filed and combined; we also examine actions a defendant may employ that may disrupt the formation of a joint suit. Our initial model involves two potential plaintiffs, with private information about the harm they have suffered, in a multi-period setting with positive costs of filing a suit. If two plaintiffs file, they join their suits to obtain a lower per-plaintiff trial cost and a higher likelihood of prevailing against the defendant. We find that some plaintiff types never file, some wait to see if another victim files and only then file, some file early and then drop their suits if not joined by another victim and, finally, some file and pursue their suits whether or not they are joined; thus, the equilibrium resembles a "bandwagon."

We then consider the effect of allowing preemptive settlement offers by the defendant aimed at discouraging follow-on suits. Preemptive settlement results in a "gold rush" of cases into the first period. In general, plaintiffs (ex ante) strictly prefer that such preemptive settlements not be allowed, and computational results suggest this may be broadly true for defendants as well; however, the inability of defendants to commit to such a policy results in an equilibrium with preemptive settlement. Finally, we consider partial unawareness of victims as to the source of harm; this provides a role for plaintiffs' attorneys, who may seek additional victims to join a combined lawsuit. Confidential preemptive settlements in the case of partial unawareness restrict the plaintiff's attorney from seeking additional victims and therefore leads to higher preemptive settlement amounts. Moreover, the defendant strictly prefers to employ preemptive settlement if the fraction of unaware victims is sufficiently high.
\end{abstract}

Keywords: Lawsuits, Settlement, Aggregation, Dynamics

JEL: K41, D82 


\section{Introduction}

In this paper we consider the dynamics of a three-party bargaining problem wherein two of the parties can form a coalition to bargain against the third party; the coalition formation is hampered by the private information of the two potential coalition members and the possible strategic interference of the third party; our context is the aggregation of lawsuits. In particular, consider a firm that produces a product that might cause harm to those exposed to the product; a harmed individual may consider bringing a lawsuit against the firm in order to recover damages and, if a number do so, a combined lawsuit may arise; this is known formally as "permissive joinder" of the lawsuits. ${ }^{1}$ In this paper we examine a dynamic model of the process by which such a joint lawsuit may form; we also examine actions a defendant may employ that may affect its formation. In our model a defendant faces zero, one, or two potential plaintiffs who have been harmed by his product ${ }^{2}$ neither the defendant nor any potential plaintiff knows (ex ante) how many victims have actually been harmed and, before filing, a plaintiff's level of harm is his private information. ${ }^{3}$ A harmed plaintiff can choose when to file (which involves a cost), and may later choose to drop the suit; if two suits are eventually ${ }^{4}$ filed (and neither, in the intervening time, has been settled) then a joint suit is formed whose members may benefit from reduced court costs as well as an increased likelihood of winning the case against the defendant firm. Our basic model shows that we can partition the interval of levels-of-harm (types) into a maximum of five distinct sets of potential

\footnotetext{
${ }^{1}$ There are a number of means, both formal and informal, whereby suits by multiple parties may be aggregated into a single action. We briefly discuss the variety of legal procedures in Section 2.

${ }^{2}$ We restrict attention to a maximum of two plaintiffs so as to focus attention on the primary forces of interest and to avoid inessential combinatorics. Formally, the model could be extended to a larger number of potential plaintiffs.

3 We assume that once a plaintiff files, his type (his level of harm suffered) becomes common knowledge. Thus, if settlement is possible before trial, then no trials will occur in equilibrium.

${ }^{4}$ In the Appendix we show that one could allow an arbitrary number of periods, but that there is no need to allow for more than two periods, so all of our analysis is in the context of a two-period model.
} 
plaintiff types: 1) types who will never file suit; 2) types who will wait to see if others file, and only file if some other victim does; 3) types who will file early, but then drop the suit if no one else "joins the bandwagon;" 4) types who file early, and will pursue the suit, albeit with "regret" (that is, if given the opportunity to recover the cost of filing by withdrawing the suit, they would do so) if no other victim has also filed; and 5) types who will file early and pursue the suit without regret even if no other plaintiff joins the bandwagon.

Using the basic two-period model we then consider a number of questions. What if the defendant can choose to settle preemptively with a single plaintiff who has filed in the first period, rather than wait to settle with that plaintiff until the end of the second period? From the defendant's perspective, delay may result in facing two plaintiffs, and settlement in the first period may (or may not) eliminate this possibility. Does such a preemptive strategy affect follow-on suits and, if so, how? What are the preferences (for the plaintiffs, for society, and for the defendant) over the alternatives of preemptive versus deferred settlement?

Within the context of preemptive settlement we first examine the impact of "data suppression" (which may arise either from confidentiality or policy) on settlements and on the dynamics of case filing. Data suppression involves the limitation of follow-on suits to not be able to employ the particulars of earlier cases to improve their individual likelihood of winning (for example, no follow-on suit could rely upon a "pattern of behavior"). We show that the partition of suits outlined above is affected, and that some would-be "waiters" (item 2 above) switch to filing early, resulting in a "gold rush," while the remainder do not file in equilibrium. In the original setup, these latter types waited and then filed in a later period if a victim had filed in the early period; now settlement in the first period means that any plaintiff type who waits does not file suit. 
We further find that, in general, plaintiffs prefer deferred settlement over preemptive settlement. From a social perspective, while more suits will be filed earlier than if settlement is deferred, it is unclear whether (in general) the overall number of suits is increased or decreased; in the case of the uniform distribution of damages we find that the ex ante expected number of suits is greater when preemptive settlement is possible. While results are less clear about the preferences of the defendant, numerical experiments with uniformly-distributed levels of harm suggests that the defendant prefers deferred settlement, too. Despite this preference, without a credible commitment to defer settlement, the defendant cannot resist the temptation to make preemptive settlement offers.

We then consider the contrasting environment wherein data is not suppressed ("data availability") so that a later (follow-on) suit can free-ride on the particulars of an earlier suit (even if that earlier suit was settled) in order to enhance the later suit's likelihood of winning at trial. We find that a gold rush is still the equilibrium outcome unless the availability of earlier case data contributes sufficiently strongly to a later-filed case's likelihood of winning. Thus, the presence of the opportunity to settle preemptively is a powerful inducement for cases to be filed early.

We also consider the possibility that one or both victims are unaware that the defendant was the cause of the harm suffered; perhaps they assume that their harm arose due to bad luck or due to their actions alone. For expositional convenience, we refer to the initial analysis as the "fullyaware" case (with or without preemptive settlement), and this portion of the analysis as the "partially-unaware" case (again, with or without preemptive settlement). Such heterogeneity of awareness of the source of harm, especially in the case of a mass-marketed product (or mass exposure), is quite realistic and it provides a role for attorneys that has been much remarked-upon in the lay and law literatures (see Nagareda, 2007): an attorney for an initial (aware) plaintiff could 
try to seek out other victims, make them aware of the possible source of harm, and encourage them to file lawsuits as well. ${ }^{5}$ How does the degree of "unawareness" affect the formation of joint suits? What now happens if the defendant can offer a preemptive settlement to an "early, aware filer" that precludes that filer's attorney from reaching out to other potential plaintiffs (a condition for a confidential settlement)? In general we find that allowing for both partial unawareness and preemptive settlement offers results in a set of waiting types of a size that is intermediate between that of the initial (no-settlement) model and that of the previously-described preemptive offer model for the fully-aware case. Moreover, increasing the degree of unawareness results in a set of "aware waiters" which varies smoothly and parametrically between the two fully-aware waiter-sets described earlier. Similar to the (fully-aware) preemptive analysis described above, only suits filed in the first period will be filed at all, since the confidentiality of settling an early suit means that otherwise unaware litigants are never made aware. ${ }^{6}$ Since a settlement negotiation that fails releases the aware, early-filing plaintiff's attorney to seek other potential plaintiffs (so as to form a joint suit), the equilibrium preemptive settlement offer is increasing in the degree of unawareness. In contrast with the fully-aware case, we show that (in general) for a sufficiently low fraction of aware victims, the defendant strictly prefers to have the option to make preemptive settlements.

Plan of the Paper

In Section 2 we provide a brief overview of the primary legal procedures (both formal and

${ }^{5}$ Unawareness also might reflect latency of the harm, as might occur with a pharmaceutical product that affects the later health of either the product's consumers or, possibly, their offspring. We do not attempt to address latency issues comprehensively, but the result that settlement in this setting (which is likely to be confidential) works to "let sleeping dogs lie" is certainly suggestive.

${ }^{6}$ Settlements that are not confidential, or where the confidentiality is ineffective or subsequently lifted, could lead to filings by previously-unaware victims; we delay consideration of this to a future paper. 
informal) used to aggregate lawsuits and we provide a brief review of related economic literature. In Section 3 we provide the model set-up and analysis for the benchmark case in which no settlement is allowed. Section 4 provides relevant details and results for the preemptive-settlement strategy in the fully-aware case when there is data suppression and when there is data availability (that is, later cases can free-ride on earlier case particulars). Section 5 considers the partiallyunaware case, both when there is no settlement and when there is confidential settlement. Finally, Section 6 provides a summary and conclusions. An Appendix with the most significant supporting material and a Technical Appendix (available at XXX) with other details augment the main text.

\section{Background on Procedural Aggregation of Lawsuits and Review of Related Literature}

\section{Procedural Aggregation of Suits by Different Parties}

There are several procedural methods by which lawsuits by different parties making related claims of the same defendant can be aggregated formally; the following discussion draws heavily on Erichson (2000). For instance, "permissive joinder" allows multiple plaintiffs to voluntarily combine their suits into a single suit. Cases pending in the same court can be aggregated through “consolidation" for purposes of judicial economy, while cases pending in different federal courts can be transferred to a single federal court for "multi-district litigation" (this is essentially consolidation of federal court cases for pre-trial proceedings only). Finally, a "class action" lawsuit involves a suit by a representative plaintiff on behalf of many others (who are ultimately bound by the outcome if they do not opt out). Generally, permissive joinder is the root from which the other aggregation procedures have sprung.

Such aggregate suits may follow the filing of many individual suits, though class actions are often initiated by one or more attorneys following the disclosure of, for example, a securities law 
violation. In this case, the identity of those harmed is ascertainable (i.e., all shareholders as of the date of the violation) and damages are proportional to the number of shares held. Finally, as Erichson demonstrates, even when there is no formal aggregation of suits, there is often substantial informal aggregation: "Plaintiffs' lawyers work together to plan strategy, conduct discovery, hire experts, develop scientific evidence, conduct jury focus groups, and join efforts in countless other ways." (2000, p. 388-389). Our model is best thought of as one of permissive joinder, as we focus on victim-driven lawsuits and we wish to allow aggregation of claims if multiple suits arise.

\section{Related Literature}

The previous literature on the economic analysis of lawsuit aggregation falls into two categories. One category involves static models of coalition-formation. Che $(1996,2002)$ examines how plaintiffs with heterogeneous claims form a class for the purpose of negotiating with a common defendant. Che and Spier (2008) provide a model with multiple victims wherein some consolidation of cases is required in order for trial to be credible. They show that the defendant can exploit coordination failure among the plaintiffs by offering a critical number of them an amount sufficient to induce settlement; the remaining victims' joint suit is thereby undermined. Instead, we assume that plaintiffs in a joint suit can coordinate their settlement decisions, allowing them to resist this unraveling process. Moreover, in our model there are some plaintiff types who proceed alone.

Our focus is on the dynamics of joint-suit formation, which is more closely-related to the second category of previous literature. Kim (2004) and Deffains and Langlais (2009) provide dynamic models with exogenous timing. In both models there are two (potential) plaintiffs with known levels of harm. Plaintiff 1 has the opportunity to file suit in period 1; Plaintiff 2 has the opportunity to file suit and join Plaintiff 1 in period 2. If the plaintiffs form a class action then they 
can pool their information/evidence and improve their likelihood of winning at trial and lower their per-person litigation costs. In the third period, the defendant makes a take-it-or-leave-it offer to plaintiffs in any extant suits. Kim (2004) shows that a Plaintiff 1 with "weak" evidence - such that a stand-alone suit would have a negative expected value - would find it optimal to file suit if it is sufficiently likely that she would be joined by a second plaintiff. Deffains and Langlais (2009) argue that a class action suit allows an early plaintiff to benefit from both scale economies in litigation and information sharing with a later plaintiff. They do not characterize all Nash equilibria for all parameter values; rather, they determine sufficient conditions for a class action to form.

Our model is quite different from those of Kim, and Deffains and Langlais, although it shares some basic features. Common features to the three models are: there are two potential victims, and suits involving two plaintiffs are expected to enjoy a higher likelihood of prevailing against the defendant and lower litigation costs per plaintiff. Differences include: in our model, neither plaintiff has private information regarding the defendant's liability, and each plaintiff has private information about damages. A crucial difference is that we do not pre-specify the order of moves (nor is any plaintiff's ability to file contingent on another's filing); either plaintiff can file at any time. Private information about damages introduces strategic motives to file versus wait; filing early can provoke follow-on lawsuits while waiting can allow learning about the likelihood of another plaintiff. Finally, we also allow the defendant to settle early with an early filer in order to preempt (or at least discourage) follow-on suits, and demonstrate that this encourages early filing.

Marceau and Mongrain (2003) provide a model with endogenous timing wherein victims with different levels of (observable) damages decide whether to initiate a costly class-action suit. Filing a class-action suit privately provides a public good to all of the other plaintiffs; once a class 
action suit is filed by an individual plaintiff, all of the other plaintiffs can join it without cost. This results in a war of attrition, wherein each plaintiff would prefer to wait and let someone else initiate the class action. In our model, an individual victim chooses to file suit (at a cost) or not; we do not view an individual victim as filing a class action suit (in the absence of other victims). On the other hand, whenever two victims have filed suit, under our maintained assumptions it is always optimal for them to join their suits; we do not include a cost of combining their suits, but it would be optimal for them to do so even at a (sufficiently small) additional cost. Our payoff structure does not result in a war of attrition. Rather, an individual files early in anticipation that there may be another (lower-damaged) plaintiff who will be motivated to join an existing suit (i.e., to get on the bandwagon) but who would not be willing to start the bandwagon rolling. Finally, we allow suits to be resolved by settlement; in particular, the defendant may settle with an early filer so as to preempt or discourage follow-on suits.

Our analysis draws upon previous work by Farrell and Saloner (1985). They consider agents deciding when (if ever) to adopt a new technology in the presence of "network externalities" (i.e., the value of adopting is higher when there are more adopters). Assuming that two potential adopters have private information about their own values of adoption, they show that equilibrium behavior resembles a "bandwagon" in which a potential adopter with a sufficiently high value adopts immediately, one with an intermediate value waits and adopts only if the other adopted previously, and one with a sufficiently low value never adopts the new technology. They are particularly interested in whether there can be insufficient or excess adoption in equilibrium (both are possible). Our model also exhibits network externalities in the sense that the value of filing suit is higher if there are more filers. This results in an endogenous-timing equilibrium of the same form, but the 
models are quite different in several other ways (besides the obvious difference in the application). First, in their model it is common knowledge that there are two potential adopters; in our model the number of harmed victims is a random variable whose distribution is common knowledge. Second, in their model an adopter would never want to switch back (in equilibrium). In our model, there are some plaintiff types who file early, but subsequently drop their cases (in order to avoid litigation costs) if not joined by another plaintiff. Third, their game is entirely between the two potential adopters; our game involves a strategic defendant in addition to the two potential plaintiffs. Settlement between the defendant and an early plaintiff can disrupt the bandwagon's development, and we find that equilibrium in this case resembles a "gold rush" in the sense that the anticipation of preemptive settlement increases the likelihood of filing in the first period.

\section{Model Set-up and Analysis}

\subsection{Basic Notation}

We assume two (potential) plaintiffs, denoted $\mathrm{P}_{\mathrm{i}}$ and $\mathrm{P}_{\mathrm{j}}$ (we will refer to $\mathrm{P}_{\mathrm{i}}$ as "him" and $\mathrm{P}_{\mathrm{j}}$ as "her"). ${ }^{7}$ These are "potential" plaintiffs in that we will allow for the realized number of victims to be 0,1 or 2 . Let $\pi_{\mathrm{n}}$ denote the probability that exactly $n$ individuals are harmed, for $n=0,1,2$. Conditional on being harmed himself, $\mathrm{P}_{\mathrm{i}}$ updates his beliefs about the likelihood that there is another potential plaintiff out there. Let $\mathrm{q}_{\mathrm{n}}$ be victim i's conditional probability that there are exactly $\mathrm{n}$ victims, given that he himself is a victim; thus $\mathrm{q}_{0}=0, \mathrm{q}_{1}=\pi_{1} /\left(\pi_{1}+2 \pi_{2}\right)$, and $\mathrm{q}_{2}=2 \pi_{2} /\left(\pi_{1}+2 \pi_{2}\right)$. Victim $\mathrm{j}$ conducts a similar updating exercise upon learning that she was harmed. $\mathrm{P}_{\mathrm{i}}$ 's harm is denoted $\delta_{\mathrm{i}}$, and $\mathrm{P}_{\mathrm{j}}$ 's harm is denoted $\delta_{\mathrm{j}}$, where $\delta_{\mathrm{i}}$ and $\delta_{\mathrm{j}}$ are drawn independently from the common

\footnotetext{
7 While our analysis is, formally, limited to a maximum of two individual victims, this could be extended to two groups of victims (think of two towns with water tables affected by nearby gas station tank leakages; for example, see Ashcraft v. Conoco, Inc., 1998 U.S. Dist. LEXIS 4092) with aggregate damages for a group used where we consider individual damages; we return to discuss this further in Section 6.
} 
distribution $\mathrm{H}(\delta)$ with positive and continuous density $\mathrm{h}(\delta)$ on the interval $[0, \infty)$. We assume that each victim's damages are his or her own private information at the point of filing suit. However, at the point of resolution (i.e., trial or settlement negotiations with the defendant), damages are observable/verifiable through either the trial mechanism itself or through pre-trial discovery.

Upon filing suit, which entails a filing cost of $f>0$, a victim becomes a plaintiff. We view this cost as not only the monetary expense of filing a suit, but also the disutility of suing; this latter cost may be small or large. We assume that the likelihood that the defendant, denoted $\mathrm{D}$, is found liable is increasing in the number of plaintiffs. This may reflect, for instance, the use of populationbased liability determination (Daughety and Reinganum, 2010). There we show that, especially in the context of many mass torts settings, cause or fault may rely on statistical evidence based on aggregate data (in the absence of being able to rely upon a clear causal chain); in this case the likelihood of liability generally increases in the frequency of harm. Because of this dependence, it is rational for a harmed Bayesian plaintiff to update any given prior distribution on defendant liability to a posterior distribution that first-order-stochastic-dominates the prior. Let $\mathrm{L}_{\mathrm{n}}$ denote the likelihood that $\mathrm{D}$ will be found liable if there are $\mathrm{n}$ plaintiffs, for $\mathrm{n}=0,1,2$; based on the foregoing discussion it is sufficient to simply posit that $\mathrm{L}_{2}>\mathrm{L}_{1}>\mathrm{L}_{0}=0$. Should the defendant be found liable, the plaintiffs are awarded their actual damages and then pay their individual shares of the litigation cost; thus, we consider joint suits that focus on the common attribute of the defendant's liability. The litigation cost per plaintiff, denoted $\mathrm{c}_{\mathrm{n}}$, for $\mathrm{n}=1,2$, is assumed to decline with the number of plaintiffs, reflecting scale economies in litigation; thus, $\mathrm{c}_{2}<\mathrm{c}_{1}$.

There are two periods during which victims can file suit; ${ }^{8}$ each victim can file suit in either

\footnotetext{
${ }^{8}$ We abstract from discounting in the analysis.
} 
period 1 or in period 2, but no further suits can be filed after period 2. This assumption simplifies the exposition but it is not crucial; in particular, it can be relaxed without affecting the results. ${ }^{9}$ In period 1, a victim must choose between filing suit immediately and waiting until period 2; if two victims file in period 2, then it will be optimal for them to join their suits (to take advantage of evidence-based externalities and scale economies in litigation). A victim who waits in period 1 is assumed to observe any filing (and settlement) that occurred in period 1; this victim then behaves optimally in period 2. In particular, this may entail joining a plaintiff who filed in period 1 (and is available to be joined, either because settlement was not allowed or because it was not successful), filing alone, or foregoing the suit altogether.

Throughout the paper we will be characterizing equilibria with a particular structure, known as bandwagon equilibria (see Section 2 above for a discussion of Farrell and Saloner, 1985); we extend these notions to the current context through the following two definitions.

Definition 1. A bandwagon strategy for victim $\mathrm{k}$ is summarized by two critical values, denoted $\underline{\delta}_{\mathrm{k}}$ and $\bar{\delta}_{\mathrm{k}}$, with $\bar{\delta}_{\mathrm{k}} \geq \underline{\delta}_{\mathrm{k}}$, and is denoted as $\left\{\underline{\delta}_{\mathrm{k}}, \bar{\delta}_{\mathrm{k}}\right\}$, such that:

(a) if $\delta_{\mathrm{k}} \geq \bar{\delta}_{\mathrm{k}}$, then victim $\mathrm{k}$ files suit in period 1 ;

(b) if $\underline{\delta}_{\mathrm{k}} \leq \delta_{\mathrm{k}}<\bar{\delta}_{\mathrm{k}}$, then victim $\mathrm{k}$ waits in period 1 and files suit in period 2 only

if another victim has already filed suit (and is available to be joined);

(c) if $\delta_{\mathrm{k}}<\underline{\delta}_{\mathrm{k}}$, then victim $\mathrm{k}$ never files suit.

Definition 2. A symmetric bandwagon equilibrium (SBE) is a pair of values $\{\underline{\delta}, \bar{\delta}\}$, with $\bar{\delta} \geq \underline{\delta}$, such that the strategies $\left\{\underline{\delta}_{\mathrm{i}}, \bar{\delta}_{\mathrm{i}}\right\}=\{\underline{\delta}, \bar{\delta}\}$ and $\left\{\underline{\delta}_{\mathrm{j}}, \bar{\delta}_{\mathrm{j}}\right\}=\{\underline{\delta}, \bar{\delta}\}$ are mutual best responses.

9 That is, there can be an arbitrary number of periods during which suit can be filed, and the results will continue to hold exactly as stated; the details of this analysis can be found in the Appendix. 


\subsection{Equilibrium Dynamics when No Settlements are Possible}

In the basic analysis we assume that no settlements are possible, so if a victim files suit in period 1 then he or she is thereafter available to be joined by a victim who files in period 2 (of course, it is also possible that both file in period 1 and form the joint suit immediately). Either way filing eventually leads to trial, so that the expected return to a plaintiff who has filed suit is the expected damages award (where the realized amount awarded is equal to the level of harm incurred) minus the plaintiff's court costs. In this subsection we present a detailed discussion of the analysis of a victim's best response function and the derivation of the symmetric bandwagon equilibrium, as well as some associated comparative statics. To help with notational conventions in later sections, where we modify the no-settlement assumption, we will use a superscript "N" on the variables and functions of interest, when needed.

In period 1, a victim can choose to file suit at a cost of $\mathrm{f}$, or wait. After the first period, there may be a plaintiff who has already filed suit or there may be no such plaintiff. Thus, in the second period an optimal strategy for a plaintiff who waited consists of a decision rule specifying whether or not to file suit contingent on how many other plaintiffs ( 0 or 1$)$ have already filed.

Note that the value of filing suit is highest for any victim when another victim has already filed suit, in which case a victim with damages $\delta$ will anticipate the payoff $L_{2} \delta-c_{2}-f$ should he or she file suit. If this is negative, then this victim will never file suit. Thus, it is clear that the lower critical value in a bandwagon equilibrium is given by $\underline{\delta} \equiv\left(c_{2}+f\right) / L_{2}$, as no victim with damages level below $\underline{\delta}$ would expect a non-negative return from filing suit. Therefore, in what follows, we need only characterize the equilibrium value $\bar{\delta}$. The upper threshold value, $\bar{\delta}$, will potentially change as we modify the model, and we will superscript it as needed; we also note that the lower threshold, 
$\underline{\delta}$, is the same for all model variants, so we do not superscript it.

Suppose that victim $\mathrm{j}$ employs a bandwagon strategy $\left\{\underline{\delta}, \bar{\delta}_{\mathrm{j}}\right\}$. We will characterize victim i's best response, beginning with period 2. If victim i filed suit in period 1 , then he has no further action to take. Suppose that victim $\mathrm{i}$ did not file suit in period 1 . If victim $\mathrm{j}$ filed suit in period 1 , then victim $i$ will file suit in period 2 only if $L_{2} \delta_{i}-c_{2}-f \geq 0$, that is only if $\delta_{i} \geq \underline{\delta}$. If victim $j$ did not file suit in period 1 , then victim $i$ does not expect victim $\mathrm{j}$ to file suit in period 2 . This is because either victim $\mathrm{j}$ does not exist or, if she does exist, she has $\delta_{\mathrm{j}}<\bar{\delta}_{\mathrm{j}}$ and therefore she was waiting for victim $\mathrm{i}$ to file; in either case, she will not file in period 2 (since she is playing a bandwagon strategy). Hence, victim i expects to proceed alone and thus he will file in period 2 only if $L_{1} \delta_{i}$ $\mathrm{c}_{1}-\mathrm{f} \geq 0$. Let $\delta_{1} \equiv\left(\mathrm{c}_{1}+\mathrm{f}\right) / \mathrm{L}_{1}$; this is the marginal plaintiff-type who would just be willing to file suit on a purely stand-alone basis. Then victim i will file suit in period 2 (alone) only if $\delta_{\mathrm{i}} \geq \delta_{1}$. Note for future purposes that, due to the earlier assumptions on the parameters $c_{k}$ and $L_{k}, \delta_{1}>\underline{\delta}$.

Now consider victim i's decision problem in period 1. Since we know that victim i will never file suit if $\delta_{\mathrm{i}}<\underline{\delta}$, we need only consider $\delta_{\mathrm{i}} \geq \underline{\delta}$. Given the subgame payoffs described above, we can write victim i's payoff from waiting in period $1, \mathrm{~W}^{\mathrm{N}}$, as:

$$
\mathrm{W}^{\mathrm{N}}\left(\delta_{\mathrm{i}}, \bar{\delta}_{\mathrm{j}}\right) \equiv \mathrm{q}_{2}\left[1-\mathrm{H}\left(\bar{\delta}_{\mathrm{j}}\right)\right]\left[\mathrm{L}_{2} \delta_{\mathrm{i}}-\mathrm{c}_{2}-\mathrm{f}\right]+\left[1-\mathrm{q}_{2}+\mathrm{q}_{2} \mathrm{H}\left(\bar{\delta}_{\mathrm{j}}\right)\right]\left[\max \left\{\mathrm{L}_{1} \delta_{\mathrm{i}}-\mathrm{c}_{1}-\mathrm{f}, 0\right\}\right] .
$$

The first term reflects the probability that victim $\mathrm{j}$ exists and has damages that would induce her to file in period 1 (using her bandwagon strategy), while the second term reflects the probability that victim $\mathrm{j}$ either does not exist or that she exists but has damages that would induce her to wait in period 1 rather than file.

On the other hand, victim i's payoff from filing in period $1, \mathrm{~F}^{\mathrm{N}}$, is given by:

$$
\mathrm{F}^{\mathrm{N}}\left(\delta_{\mathrm{i}}, \bar{\delta}_{\mathrm{j}}\right) \equiv \mathrm{q}_{2}[1-\mathrm{H}(\underline{\delta})]\left[\mathrm{L}_{2} \delta_{\mathrm{i}}-\mathrm{c}_{2}-\mathrm{f}\right]+\left[1-\mathrm{q}_{2}+\mathrm{q}_{2} \mathrm{H}(\underline{\delta})\right]\left[\max \left\{\mathrm{L}_{1} \delta_{\mathrm{i}}-\mathrm{c}_{1}, 0\right\}-\mathrm{f}\right] .
$$


To see why, notice that if victim i files in period 1 , then regardless of what else happens he will pay the fee $f$. If victim $\mathrm{j}$ exists (this occurs with probability $\mathrm{q}_{2}$ ), then she will also file in period 1 if $\delta_{\mathrm{j}}$ $\geq \bar{\delta}_{\mathrm{j}}$ and she will wait in period 1 but will file in period 2 (joining victim i) if $\underline{\delta} \leq \delta_{\mathrm{j}}<\bar{\delta}_{\mathrm{j}}$. Thus, victim $\mathrm{j}$ will ultimately file with probability $1-\mathrm{H}(\underline{\delta})$, in which case victim $\mathrm{i}$ will receive the payoff $\mathrm{L}_{2} \delta_{\mathrm{i}}-\mathrm{c}_{2}-\mathrm{f}$. On the other hand, if either there is no victim $\mathrm{j}$ (which occurs with probability $1-\mathrm{q}_{2}$ ) or if there is a victim j but her damages are less than $\underline{\delta}$ (which occurs with probability $\mathrm{q}_{2} \mathrm{H}(\underline{\delta})$ ), then victim $\mathrm{j}$ will never file. In this case, victim $\mathrm{i}$ will decide between dropping his case and receiving 0 or continuing and receiving $\mathrm{L}_{1} \delta_{\mathrm{i}}-\mathrm{c}_{1}$. Note that $\mathrm{F}^{\mathrm{N}}\left(\delta_{\mathrm{i}}, \bar{\delta}_{\mathrm{j}}\right)$ is actually independent of $\bar{\delta}_{\mathrm{j}}$.

Let $\mathrm{Z}^{\mathrm{N}}\left(\delta_{\mathrm{i}}, \bar{\delta}_{\mathrm{j}}\right) \equiv \mathrm{F}^{\mathrm{N}}\left(\delta_{\mathrm{i}}, \bar{\delta}_{\mathrm{j}}\right)-\mathrm{W}^{\mathrm{N}}\left(\delta_{\mathrm{i}}, \bar{\delta}_{\mathrm{j}}\right)$ denote the net value of filing in period 1 (net of the value of waiting and then behaving optimally in period 2). Then:

$$
\begin{aligned}
\mathrm{Z}^{\mathrm{N}}\left(\delta_{\mathrm{i}}, \bar{\delta}_{\mathrm{j}}\right) \equiv \mathrm{q}_{2}[1-\mathrm{H}(\underline{\delta})]\left[\mathrm{L}_{2} \delta_{\mathrm{i}}-\mathrm{c}_{2}-\mathrm{f}\right]+\left[1-\mathrm{q}_{2}+\mathrm{q}_{2} \mathrm{H}(\underline{\delta})\right]\left[\max \left\{\mathrm{L}_{1} \delta_{\mathrm{i}}-\mathrm{c}_{1}, 0\right\}-\mathrm{f}\right] \\
-\mathrm{q}_{2}\left[1-\mathrm{H}\left(\bar{\delta}_{\mathrm{j}}\right)\right]\left[\mathrm{L}_{2} \delta_{\mathrm{i}}-\mathrm{c}_{2}-\mathrm{f}\right]-\left[1-\mathrm{q}_{2}+\mathrm{q}_{2} \mathrm{H}\left(\bar{\delta}_{\mathrm{j}}\right)\right]\left[\max \left\{\mathrm{L}_{1} \delta_{\mathrm{i}}-\mathrm{c}_{1}-\mathrm{f}, 0\right\}\right] \\
=\mathrm{q}_{2}\left[\mathrm{H}\left(\bar{\delta}_{\mathrm{j}}\right)-\mathrm{H}(\underline{\delta})\right]\left[\mathrm{L}_{2} \delta_{\mathrm{i}}-\mathrm{c}_{2}-\mathrm{f}\right]+\left[1-\mathrm{q}_{2}+\mathrm{q}_{2} \mathrm{H}(\underline{\delta})\right]\left[\max \left\{\mathrm{L}_{1} \delta_{\mathrm{i}}-\mathrm{c}_{1}, 0\right\}-\mathrm{f}\right] \\
-\left[1-\mathrm{q}_{2}+\mathrm{q}_{2} \mathrm{H}\left(\bar{\delta}_{\mathrm{j}}\right)\right]\left[\max \left\{\mathrm{L}_{1} \delta_{\mathrm{i}}-\mathrm{c}_{1}-\mathrm{f}, 0\right\}\right] .
\end{aligned}
$$

We will now determine victim i's best response to victim j's bandwagon strategy $\bar{\delta}_{\mathrm{j}}$ (having already established that $\left.\underline{\delta}_{\mathrm{i}}=\underline{\delta}_{\mathrm{j}}=\underline{\delta}=\left(\mathrm{c}_{2}+\mathrm{f}\right) / \mathrm{L}_{2}\right)$. First, suppose that $\bar{\delta}_{\mathrm{j}}=\underline{\delta}$; this is a limiting case wherein victim $\mathrm{j}$ (if she exists) never waits strategically; she either files in period 1 or she never files. In this case $\mathrm{Z}^{\mathrm{N}}\left(\delta_{\mathrm{i}}, \underline{\delta}\right)=\left[1-\mathrm{q}_{2}+\mathrm{q}_{2} \mathrm{H}(\underline{\delta})\right]\left[\max \left\{\mathrm{L}_{1} \delta_{\mathrm{i}}-\mathrm{c}_{1}, 0\right\}-\mathrm{f}-\max \left\{\mathrm{L}_{1} \delta_{\mathrm{i}}-\mathrm{c}_{1}-\mathrm{f}, 0\right\}\right]<0$ for $\delta_{\mathrm{i}}<\delta_{1}$ and $\mathrm{Z}^{\mathrm{N}}\left(\delta_{\mathrm{i}}, \underline{\delta}\right)=0$ for $\delta_{\mathrm{i}} \geq \delta_{1}$. Thus, a best response for victim $\mathrm{i}$ is to file in period 1 only if $\delta_{\mathrm{i}}$ $\geq \delta_{1}$ (we assume that a victim files suit when indifferent); otherwise it is optimal to wait in period 1 and proceed optimally (that is, file suit in period 2 if victim $\mathrm{j}$ filed in period 1 and $\delta_{i} \geq \underline{\delta}$ ). Notice that any victim who is willing to file alone in period 2 will (optimally) file in period 1. 
Now consider any $\bar{\delta}_{\mathrm{j}}>\underline{\delta}$; notice that $\mathrm{Z}^{\mathrm{N}}\left(\delta_{\mathrm{i}}, \bar{\delta}_{\mathrm{j}}\right)=\mathrm{q}_{2}\left[\mathrm{H}\left(\bar{\delta}_{\mathrm{j}}\right)-\mathrm{H}(\underline{\delta})\right]\left[\mathrm{L}_{2} \delta_{\mathrm{i}}-\mathrm{c}_{2}-\mathrm{L}_{1} \delta_{\mathrm{i}}+\mathrm{c}_{1}\right]>0$ for all $\delta_{\mathrm{i}} \geq \delta_{1}$. Thus, any victim $\mathrm{i}$ with $\delta_{\mathrm{i}} \geq \delta_{1}$ will file suit in period 1 . Next, consider $\delta_{\mathrm{i}} \in\left[\underline{\delta}, \delta_{1}\right)$. Then

$$
\mathrm{Z}^{\mathrm{N}}\left(\delta_{\mathrm{i}}, \bar{\delta}_{\mathrm{j}}\right)=\mathrm{q}_{2}\left[\mathrm{H}\left(\bar{\delta}_{\mathrm{j}}\right)-\mathrm{H}(\underline{\delta})\right]\left[\mathrm{L}_{2} \delta_{\mathrm{i}}-\mathrm{c}_{2}-\mathrm{f}\right]+\left[1-\mathrm{q}_{2}+\mathrm{q}_{2} \mathrm{H}(\underline{\delta})\right]\left[\max \left\{\mathrm{L}_{1} \delta_{\mathrm{i}}-\mathrm{c}_{1}, 0\right\}-\mathrm{f}\right],
$$

since $\max \left\{\mathrm{L}_{1} \delta_{\mathrm{i}}-\mathrm{c}_{1}-\mathrm{f}, 0\right\}=0$. Therefore: (a) $\mathrm{Z}^{\mathrm{N}}\left(\underline{\delta}, \bar{\delta}_{\mathrm{j}}\right)=-\mathrm{f}\left[1-\mathrm{q}_{2}+\mathrm{q}_{2} \mathrm{H}(\underline{\delta})\right]<0$; (b) $\mathrm{Z}^{\mathrm{N}}\left(\delta_{\mathrm{i}}, \bar{\delta}_{\mathrm{j}}\right)$ is strictly increasing in its first argument; and (c) $Z^{\mathrm{N}}\left(\delta_{1}, \bar{\delta}_{\mathrm{j}}\right)>0$. These facts imply that there is a unique value $\varphi\left(\bar{\delta}_{\mathrm{j}}\right) \in\left(\underline{\delta}, \delta_{1}\right)$ such that $\mathrm{Z}^{\mathrm{N}}\left(\varphi\left(\bar{\delta}_{\mathrm{j}}\right), \bar{\delta}_{\mathrm{j}}\right)=0$. A victim $\mathrm{i}$ with $\delta_{\mathrm{i}} \geq \varphi\left(\bar{\delta}_{\mathrm{j}}\right)$ will file in period 1 and a victim i with $\delta_{\mathrm{i}}<\varphi\left(\bar{\delta}_{\mathrm{j}}\right)$ will wait in period 1 (and file in period 2 only if $\delta_{\mathrm{i}} \geq \underline{\delta}$ and there is another plaintiff to join).

Thus, victim i's best response can be characterized by a threshold value of $\delta_{i}$; for simplicity (and with some abuse of terminology), we will refer to this threshold as victim i's best response. Let $\varphi\left(\bar{\delta}_{\mathrm{j}}\right)$ denote victim i's best response to victim j's bandwagon strategy, which is summarized by $\bar{\delta}_{\mathrm{j}}$. We have already concluded that $\varphi(\underline{\delta})=\delta_{1}$ and that $\varphi\left(\bar{\delta}_{\mathrm{j}}\right) \in\left(\underline{\delta}, \delta_{1}\right)$ for $\bar{\delta}_{\mathrm{j}}>\underline{\delta}$. This implies that victim i's best response to a bandwagon strategy for victim $\mathrm{j}$ is itself a bandwagon strategy, because victim $\mathrm{i}$ will never wait in period 1 and then file suit in period 2 if victim $\mathrm{j}$ does not file suit in period 1 ; any victim $\mathrm{i}$ who would be willing to file suit alone in period 2 prefers to file suit in period 1 .

To complete the description of the symmetric bandwagon equilibrium we need to find a threshold $\bar{\delta}$ such that $\bar{\delta}=\varphi(\bar{\delta})$. Since $\varphi(\underline{\delta})=\delta_{1}$, there cannot be a SBE in which $\bar{\delta}=\underline{\delta}$. When $\bar{\delta}>$ $\underline{\delta}$, since $Z^{\mathrm{N}}(\bullet, \bullet)$ is continuous and strictly increasing in both its arguments, and since $\varphi\left(\bar{\delta}_{\mathrm{j}}\right)$ is defined by $\mathrm{Z}^{\mathrm{N}}\left(\varphi\left(\bar{\delta}_{\mathrm{j}}\right), \bar{\delta}_{\mathrm{j}}\right)=0$, it follows that $\varphi\left(\bar{\delta}_{\mathrm{j}}\right)$ is a continuous and decreasing function so that there exists a unique value $\bar{\delta}^{\mathrm{N}} \in\left(\underline{\delta}, \delta_{1}\right)$ such that $\bar{\delta}^{\mathrm{N}}=\varphi\left(\bar{\delta}^{\mathrm{N}}\right)$. We summarize the foregoing as follows.

Proposition 1. $\left\{\underline{\delta}, \bar{\delta}^{\mathrm{N}}\right\}$ is the unique SBE with no settlement, with $\underline{\delta}=\left(\mathrm{c}_{2}+\mathrm{f}\right) / \mathrm{L}_{2}$, and $\bar{\delta}^{\mathrm{N}}$ the unique solution to $\mathrm{Z}^{\mathrm{N}}(\delta, \delta)=0$. Moreover, $\bar{\delta}^{\mathrm{N}} \in\left(\underline{\delta}, \delta_{1}\right)$, where $\delta_{1} \equiv\left(\mathrm{c}_{1}+\mathrm{f}\right) / \mathrm{L}_{1}$. 
That is, there is a unique set of "waiting types," $\left[\underline{\delta}, \bar{\delta}^{\mathrm{N}}\right)$; any victim with a type in this set waits in period 1 and files in period 2 only if some other victim has filed in period 1.

The fact that $\bar{\delta}^{\mathrm{N}}<\delta_{1}$ means that (in equilibrium) there will be some types of victim $\mathrm{i}$ that will file in the first period, but will regret having filed in period 1 if not joined in period 2 by another plaintiff. It remains to characterize when there will actually be cases that are filed in period 1 and subsequently dropped in period 2 when a second plaintiff fails to materialize; that is, when is $\bar{\delta}^{\mathrm{N}}<$ $\delta_{\mathrm{Q}} \equiv \mathrm{c}_{1} / \mathrm{L}_{1}$ ? Unfortunately, since (for general $\mathrm{H}$ ) $\bar{\delta}^{\mathrm{N}}$ is implicitly defined by $\mathrm{Z}^{\mathrm{N}}\left(\bar{\delta}^{\mathrm{N}}, \bar{\delta}^{\mathrm{N}}\right)=0$, an explicit condition is not generally possible. However, as shown in the Technical Appendix, there always exists a value of $\mathrm{f}$, denoted as $\mathrm{f}_{\mathrm{NQ}}$, such that $\bar{\delta}^{\mathrm{N}}(>,=,<) \delta_{\mathrm{Q}}$ as $\mathrm{f}(>,=,<) \mathrm{f}_{\mathrm{NQ}}$.

Since the outcome wherein there are victim types who file but then drop the suit (which only occurs if $\bar{\delta}^{\mathrm{N}}<\delta_{\mathrm{Q}}$ ) is of interest, we examine it at some length. Most of our results do not depend upon $\mathrm{f}<\mathrm{f}_{\mathrm{NQ}}$; therefore, we will specifically note when particular results rely on this assumption. The following proposition summarizes the partitioning of the possible levels of harm $[0, \infty)$ and Figure 1 below illustrates the dynamics of joint suit formation when no settlements are possible. Proposition 2. In the $\operatorname{SBE}\left\{\underline{\delta}, \bar{\delta}^{\mathrm{N}}\right\}$, victim i takes the following actions, depending on the harm $\delta_{\mathrm{i}}$ :

a) $\delta_{\mathrm{i}} \in[0, \underline{\delta}) \Rightarrow$ never file;

b) $\delta_{\mathrm{i}} \in\left[\underline{\delta}, \bar{\delta}^{\mathrm{N}}\right) \Rightarrow$ wait in period 1 , file in period 2 only if another victim filed in period 1 ;

c) (i) $\mathrm{f}<\mathrm{f}_{\mathrm{NQ}}$ and $\delta_{\mathrm{i}} \in\left[\bar{\delta}^{\mathrm{N}}, \delta_{\mathrm{Q}}\right) \Rightarrow$ file in period 1 , drop in period 2 only if no other victim filed in period 1 or 2 ;

(ii) $\mathrm{f}<\mathrm{f}_{\mathrm{NQ}}$ and $\delta_{\mathrm{i}} \in\left[\delta_{\mathrm{Q}}, \infty\right) \Rightarrow$ file in period 1 , continue to sue in period 2;

(iii) $\mathrm{f} \geq \mathrm{f}_{\mathrm{NQ}}$ and $\delta_{\mathrm{i}} \in\left[\bar{\delta}^{\mathrm{N}}, \infty\right) \Rightarrow$ file in period 1 , continue to sue in period 2 .

Figure 1 illustrates the partitioning of the type space $[0, \infty)$, showing the actions taken in 
equilibrium; we have assumed $\bar{\delta}^{\mathrm{N}}<\delta_{\mathrm{Q}}$ for the illustration, but if this does not hold (that is, if $\mathrm{f} \geq \mathrm{f}_{\mathrm{NQ}}$ ), then the region shown between $\bar{\delta}^{\mathrm{N}}$ and $\delta_{\mathrm{Q}}$ would not appear.

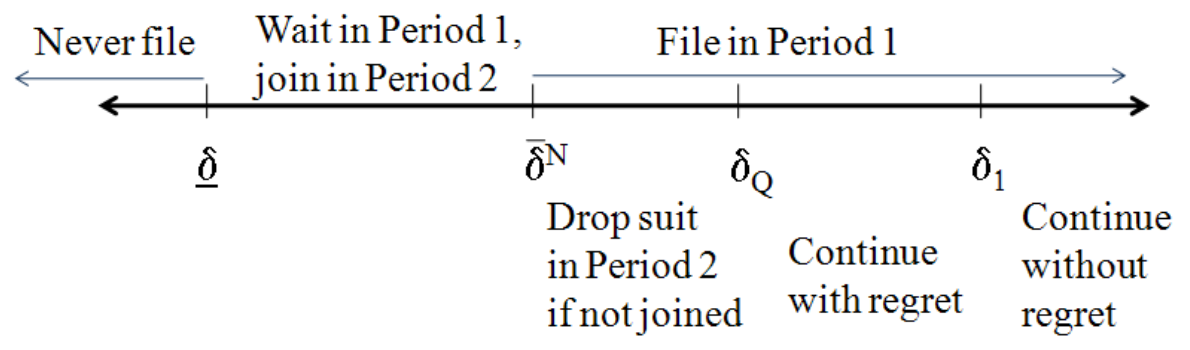

Figure 1: Partitioning the Level of Harm Under No Settlement

\section{Comparative Statics}

The following comparative statics results are shown in the Technical Appendix.

Proposition 3. Comparative statics results for $\mathrm{f}, \mathrm{L}_{2}, \mathrm{c}_{2}$, and $\mathrm{q}_{2}$.

(a) $\partial \underline{\delta} / \partial \mathrm{f}>0 ; \partial \underline{\delta} / \partial \mathrm{c}_{2}>0 ; \partial \underline{\delta} / \partial \mathrm{L}_{2}<0 ; \partial \underline{\delta} / \partial \mathrm{q}_{2}=0$;

(b) $\partial \bar{\delta}^{\mathrm{N}} / \partial \mathrm{f}>0 ; \partial \bar{\delta}^{\mathrm{N}} / \partial \mathrm{c}_{2}>0 ; \partial \bar{\delta}^{\mathrm{N}} / \partial \mathrm{L}_{2}<0 ; \partial \bar{\delta}^{\mathrm{N}} / \partial \mathrm{q}_{2}<0$.

Taking the results in Proposition 3 as a whole, if we consider $\left[\underline{\delta}, \bar{\delta}^{\mathrm{N}}\right)$ as a "window for waiting," then an increase in the filing cost, $\mathrm{f}$, shifts both the bottom and the top of the window "to the right" (though not necessarily uniformly): more types will never file, and some types who would have filed in period 1 before the increase in f now wait. Similarly, a reduction in the scale-economies in litigation costs due to coordination of the suits (that is, an increase in $c_{2}$, which reduces $c_{1}-c_{2}$ ), yields a similar (potentially non-uniform) rightward shift of the window. Note that this is because the value of waiting drops, but the value of filing in the first period falls by yet more, so that the previous marginal type, $\bar{\delta}^{\mathrm{N}}$, now strictly wishes to wait. If $\mathrm{L}_{2}$ increases instead, then the window shifts left (again, not necessarily in a uniform manner): there is increased value to joining with another plaintiff, if she exists, so some of the types who would never have filed before now join the 
window, while some near the top of the window now file in period 1 (for small changes in $\mathrm{L}_{2}$ and for $\mathrm{f}<\mathrm{f}_{\mathrm{NQ}}$, this means that if no other victim files in period 1 or 2 , then this lone plaintiff will drop the suit; if $\mathrm{f} \geq \mathrm{f}_{\mathrm{NQ}}$, then this plaintiff will pursue the case to resolution). Alternatively, if forming a joint suit obtains the benefit of the cost improvement $c_{1}-c_{2}$, but no change in the likelihood of liability (i.e., $\mathrm{L}_{2}$ equals $\mathrm{L}_{1}$ ), then the comparative statics imply that more plaintiff types never file ( $\underline{\delta}$ increases) and some types that would have filed in the first period now choose to wait $\left(\bar{\delta}^{\mathrm{N}}\right.$ increases). Finally, an increase in $\mathrm{q}_{2}$ does not affect the bottom of the window (since $\underline{\delta}$ is independent of $\mathrm{q}_{2}$ ), but it does shift the top of the window to the left: since there is a higher likelihood of a second plaintiff, the type just willing to file in the first period (that is, the previous marginal type $\bar{\delta}^{\mathrm{N}}$ ) is less worried about being a lone filer, so he now strictly prefers to file early.

\section{Preemptive Settlement}

In the analysis of Section 3 no settlement was allowed; all filed cases that were pursued went to trial, sometimes singly and sometimes via a joint suit. Instead, now consider the possibility of settlement offers made by D. Suppose that (at the point of bargaining) damages are common knowledge and that D need only offer what that plaintiff could expect from continuing with the suit. This might occur because the process of filing a claim (including a specification of damages) and subsequent discovery were sufficient to reveal the level of harm the plaintiff has suffered. It is immediate that D will prefer settlement at the end of the second period to no settlement since D's offer will deduct the plaintiff's court costs from the damages and D will save his court costs. This further means that the plaintiff will be indifferent between no settlement and settlement at the end of the second period. "Deferred settlement" will refer to any settlement (with one or two plaintiffs) that could as well have happened at the end of period 2. Thus, if both plaintiffs file in period 1, or 
one plaintiff files in period 1 and a second files in period 2, or if one or both were to file in period 2, we will refer to any settlement as a deferred settlement.

In this section we modify the analysis in Section 3 by allowing D to make a settlement offer to a plaintiff who files alone in the first period. We consider two alternatives concerning the information that is embodied in an early-filing, lone suit. In the first alternative, we assume that a later-filing plaintiff (that is, a lone filer in the second period) cannot improve their likelihood of winning against the defendant; thus, while two plaintiffs together can achieve a reduction in costs and an improvement in the likelihood of finding the defendant liable, this is not true for a lone follow-on suit. The source of this disparity could be that the first suit settled confidentially or that courts have a policy of restricting follow-on suits to their merits alone. ${ }^{10}$ We refer to this as "data suppression." The second alternative reconsiders preemptive settlement, but now allows the followon suit to improve its likelihood of winning due to a previously-filed suit's presence (even if that suit settled). Thus, for example, if the second suit has developed information on the effect of a drug on the plaintiff, and that plaintiff can refer to the effect of the same drug on the earlier plaintiff, then we refer to this as a case of "data availability." We consider the contrast of data suppression and data availability to sharpen our understanding of the impact of preemptive settlement.

\subsection{Equilibrium Dynamics when Data-Suppressing Settlements are Possible}

Now suppose it is common knowledge that, at every stage, D can offer a settlement to any plaintiff who has filed suit; we assume that settlement negotiation occurs at the end of each period. Moreover, first-period settlements involve data-suppression in the sense that any plaintiff who files in period 2 cannot enjoy either an evidence-related externality (i.e., she cannot rely on the existence

\footnotetext{
${ }^{10}$ For a discussion of bargaining over money and confidentiality, see Daughety and Reinganum $(1999,2002)$.
} 
of the other plaintiff to improve her odds of winning) or a cost-sharing externality with a plaintiff who filed but settled in the first period. An offer by the defendant to settle with a lone plaintiff who has filed in the first period will be referred to as "preemptive settlement" and we use a superscript "S" on the relevant functions and variables to indicate the we are considering the case of preemptive settlement with data suppression.

As before, we know that victim i will never file suit if $\delta_{\mathrm{i}}<\underline{\delta}$, and thus we need only consider $\delta_{\mathrm{i}} \geq \underline{\delta}$. Let $\mathrm{s}_{\mathrm{n}}^{\mathrm{t}}(\delta)$ denote the settlement offered to a plaintiff with damages $\delta$ at the end of period $\mathrm{t}$ when $\mathrm{n}$ plaintiffs have filed suit; $\mathrm{t}=1,2$; and $\mathrm{n}=1,2$. If both plaintiffs file in period 1 , we assume that they do not suffer from coordination failure; that is, $\mathrm{P}_{\mathrm{i}}$ can extract a settlement of $\mathrm{s}_{2}^{1}\left(\delta_{\mathrm{i}}\right) \equiv \mathrm{L}_{2} \delta_{\mathrm{i}}$ $\mathrm{c}_{2}$ and $\mathrm{P}_{\mathrm{j}}$ can extract a settlement of $\mathrm{s}_{2}^{1}\left(\delta_{\mathrm{j}}\right) \equiv \mathrm{L}_{2} \delta_{\mathrm{j}}-\mathrm{c}_{2}$. If victim i files alone in the second period, he receives a settlement of only $\mathrm{s}_{1}^{2}\left(\delta_{\mathrm{i}}\right) \equiv \max \left\{\mathrm{L}_{1} \delta_{\mathrm{i}}-\mathrm{c}_{1}, 0\right\}$. Finally, if only one victim (say, victim i) files in period 1, then D need only offer him his expected continuation value (computed below).

Suppose $\mathrm{P}_{\mathrm{i}}$ learns that he filed alone in period 1 ; he uses this observation to update his beliefs about $P_{j}$. This event occurs if either: 1) there is no victim j; or 2) there is a victim j, but she has damages $\delta_{\mathrm{j}}<\bar{\delta}_{\mathrm{j}}$. These events have combined probability $\left[1-\mathrm{q}_{2}+\mathrm{q}_{2} \mathrm{H}\left(\bar{\delta}_{\mathrm{j}}\right)\right]$. Thus, upon learning that he filed alone in period $1, \mathrm{P}_{\mathrm{i}}$ anticipates that he will be joined by $\mathrm{P}_{\mathrm{j}}$ in period 2 with probability $\mathrm{q}_{2}\left[\mathrm{H}\left(\bar{\delta}_{\mathrm{j}}\right)-\mathrm{H}(\underline{\delta})\right] /\left[1-\mathrm{q}_{2}+\mathrm{q}_{2} \mathrm{H}\left(\bar{\delta}_{\mathrm{j}}\right)\right]$ and would ultimately receive a settlement of $\mathrm{s}_{2}^{2}\left(\delta_{\mathrm{i}}\right) \equiv \mathrm{L}_{2} \delta_{\mathrm{i}}-\mathrm{c}_{2}$. On the other hand, $P_{i}$ anticipates that he will not be joined by a $P_{j}$ in period 2 with probability $\left[1-q_{2}+\right.$ $\left.\mathrm{q}_{2} \mathrm{H}(\underline{\delta})\right] /\left[1-\mathrm{q}_{2}+\mathrm{q}_{2} \mathrm{H}\left(\bar{\delta}_{\mathrm{j}}\right)\right]$, and therefore would ultimately receive a settlement of $\mathrm{s}_{1}^{2}\left(\delta_{\mathrm{i}}\right) \equiv \max \left\{\mathrm{L}_{1} \delta_{\mathrm{i}}-\right.$ $\left.c_{1}, 0\right\}$. Combining these gives $\mathrm{P}_{\mathrm{i}}$ 's expected continuation value if he filed alone in period 1 ; if $\mathrm{D}$ can make a take-it-or-leave-it settlement offer, this is what D must offer to induce $\mathrm{P}_{\mathrm{i}}$ to settle. Since this will depend on the bandwagon strategy being played by a possible $\mathrm{P}_{\mathrm{j}}$ (which is taken as given by 
both $\mathrm{P}_{\mathrm{i}}$ and $\left.\mathrm{D}\right)$, we denote this amount by $\mathrm{s}_{1}^{1}\left(\delta_{\mathrm{i}}, \bar{\delta}_{\mathrm{j}}\right)$.

$$
\begin{aligned}
\mathrm{s}_{1}^{1}\left(\delta_{\mathrm{i}}, \bar{\delta}_{\mathrm{j}}\right) \equiv\left\{\mathrm{q}_{2}\left[\mathrm{H}\left(\bar{\delta}_{\mathrm{j}}\right)-\mathrm{H}(\underline{\delta})\right] /\left[1-\mathrm{q}_{2}+\mathrm{q}_{2} \mathrm{H}\left(\bar{\delta}_{\mathrm{j}}\right)\right]\right\}\left[\mathrm{L}_{2} \delta_{\mathrm{i}}-\mathrm{c}_{2}\right] \\
+\left\{\left[1-\mathrm{q}_{2}+\mathrm{q}_{2} \mathrm{H}(\underline{\delta})\right] /\left[1-\mathrm{q}_{2}+\mathrm{q}_{2} \mathrm{H}\left(\bar{\delta}_{\mathrm{j}}\right)\right]\right\}\left[\max \left\{\mathrm{L}_{1} \delta_{\mathrm{i}}-\mathrm{c}_{1}, 0\right\}\right] .
\end{aligned}
$$

Note that, given any bandwagon strategy for a possible $\mathrm{P}_{\mathrm{j}}$, at the end of period 1 it is always in D's interest to induce $\mathrm{P}_{\mathrm{i}}$ to settle, since otherwise $\mathrm{D}$ expects to have to pay $\mathrm{P}_{\mathrm{i}}$ 's continuation value plus the expected settlement payment to $\mathrm{P}_{\mathrm{j}}$, which is given by $\left\{\mathrm{q}_{2}\left[\mathrm{H}\left(\bar{\delta}_{\mathrm{j}}\right)-\mathrm{H}(\underline{\delta})\right] /\left[1-\mathrm{q}_{2}+\right.\right.$ $\left.\left.\mathrm{q}_{2} \mathrm{H}\left(\bar{\delta}_{\mathrm{j}}\right)\right]\right\}\left[\mathrm{L}_{2} \delta_{\mathrm{j}}-\mathrm{c}_{2}\right]$. By inducing $\mathrm{P}_{\mathrm{i}}$ to settle, $\mathrm{D}$ will discourage further suits, at least to some extent, because the evidence externalities and scale economies in litigation costs will be unavailable to $\mathrm{P}_{\mathrm{j}}$. Thus, without a credible commitment to defer settlement, when confronted with a lone filer in period 1, D cannot resist settling the suit.

Now consider $\mathrm{P}_{\mathrm{i}}$ 's optimal decision in period 1, anticipating that $\mathrm{D}$ will settle any lone suits filed in period 1. If $\mathrm{P}_{\mathrm{i}}$ waits in period 1 , he does not expect to be able to join another plaintiff in period 2; either $\mathrm{P}_{\mathrm{j}}$ does not exist, or she exists but did not file suit (in which case she was waiting to follow $\mathrm{P}_{\mathrm{i}}$ and will not file in period 2 since $\mathrm{P}_{\mathrm{i}}$ did not file in period 1), or she exists and filed suit in period 1 but settled her suit. Thus, if $\mathrm{P}_{\mathrm{i}}$ waits in period 1 , then he will file suit in period 2 only if $\delta_{\mathrm{i}} \geq \delta_{1} ; \mathrm{P}_{\mathrm{i}}$ 's expected payoff from waiting in period 1 is:

$$
\mathrm{W}^{\mathrm{S}}\left(\delta_{\mathrm{i}}, \bar{\delta}_{\mathrm{j}}\right)=\max \left\{\mathrm{L}_{1} \delta_{\mathrm{i}}-\mathrm{c}_{1}-\mathrm{f}, 0\right\}
$$

that is, unlike the basic model with no settlement, the payoff from waiting is independent of $\bar{\delta}_{\mathrm{j}}$. $\mathrm{P}_{\mathrm{i}}$ 's expected payoff if he files in period 1 is:

$$
\begin{aligned}
\mathrm{F}^{\mathrm{S}}\left(\delta_{\mathrm{i}}, \bar{\delta}_{\mathrm{j}}\right)=\mathrm{q}_{2}\left[1-\mathrm{H}\left(\bar{\delta}_{\mathrm{j}}\right)\right]\left[\mathrm{L}_{2} \delta_{\mathrm{i}}-\mathrm{c}_{2}-\mathrm{f}\right]+\left[1-\mathrm{q}_{2}+\mathrm{q}_{2} \mathrm{H}\left(\bar{\delta}_{\mathrm{j}}\right)\right]\left[\mathrm{s}_{1}^{1}\left(\delta_{\mathrm{i}}, \bar{\delta}_{\mathrm{j}}\right)-\mathrm{f}\right] \\
=\mathrm{q}_{2}[1-\mathrm{H}(\underline{\delta})]\left[\mathrm{L}_{2} \delta_{\mathrm{i}}-\mathrm{c}_{2}-\mathrm{f}\right]+\left[1-\mathrm{q}_{2}+\mathrm{q}_{2} \mathrm{H}(\underline{\delta})\right]\left[\max \left\{\mathrm{L}_{1} \delta_{\mathrm{i}}-\mathrm{c}_{1}, 0\right\}-\mathrm{f}\right] .
\end{aligned}
$$

Note that $\mathrm{F}^{\mathrm{S}}\left(\delta_{\mathrm{i}}, \bar{\delta}_{\mathrm{j}}\right)$ is exactly the same as $\mathrm{F}^{\mathrm{N}}\left(\delta_{\mathrm{i}}, \bar{\delta}_{\mathrm{j}}\right)$ and thus is independent of $\bar{\delta}_{\mathrm{j}}$. These expressions 
are equal because of the assumption that $\mathrm{D}$ needs only to offer $\mathrm{P}_{\mathrm{i}}$ 's continuation value in settlement.

Let $Z^{\mathrm{S}}\left(\delta_{\mathrm{i}}, \bar{\delta}_{\mathrm{j}}\right) \equiv \mathrm{F}^{\mathrm{S}}\left(\delta_{\mathrm{i}}, \bar{\delta}_{\mathrm{j}}\right)-\mathrm{W}^{\mathrm{S}}\left(\delta_{\mathrm{i}}, \bar{\delta}_{\mathrm{j}}\right)$ denote the net value of filing in period 1 (net of the value of waiting and then behaving optimally in period 2) in the preemptive settlement regime. Then:

$$
\begin{aligned}
\mathrm{Z}^{\mathrm{S}}\left(\delta_{\mathrm{i}}, \bar{\delta}_{\mathrm{j}}\right)=\mathrm{q}_{2}[1-\mathrm{H}(\underline{\delta})]\left[\mathrm{L}_{2} \delta_{\mathrm{i}}-\mathrm{c}_{2}-\mathrm{f}\right] \\
+\left[1-\mathrm{q}_{2}+\mathrm{q}_{2} \mathrm{H}(\underline{\delta})\right]\left[\max \left\{\mathrm{L}_{1} \delta_{\mathrm{i}}-\mathrm{c}_{1}, 0\right\}-\mathrm{f}\right]-\max \left\{\mathrm{L}_{1} \delta_{\mathrm{i}}-\mathrm{c}_{1}-\mathrm{f}, 0\right\} .
\end{aligned}
$$

First, consider $\delta_{\mathrm{i}} \geq \delta_{1}$; then $\mathrm{Z}^{\mathrm{S}}\left(\delta_{\mathrm{i}}, \bar{\delta}_{\mathrm{j}}\right)=\mathrm{q}_{2}[1-\mathrm{H}(\underline{\delta})]\left[\mathrm{L}_{2} \delta_{\mathrm{i}}-\mathrm{c}_{2}-\mathrm{L}_{1} \delta_{\mathrm{i}}+\mathrm{c}_{1}\right]>0$. That is, any victim $\mathrm{i}$ with damages $\delta_{i} \geq \delta_{1}$ would strictly prefer to file suit in period 1 . If $\delta_{i} \in\left[\underline{\delta}, \delta_{1}\right)$ then the value of waiting in period 1 is zero, since $\mathrm{W}^{\mathrm{S}}\left(\delta_{\mathrm{i}}, \bar{\delta}_{\mathrm{j}}\right)=\max \left\{\mathrm{L}_{1} \delta_{\mathrm{i}}-\mathrm{c}_{1}-\mathrm{f}, 0\right\}=0$. Thus, for $\delta_{\mathrm{i}} \in\left[\underline{\delta}, \delta_{1}\right)$, the net gain to filing in period 1 is:

$$
\mathrm{Z}^{\mathrm{S}}\left(\delta_{\mathrm{i}}, \bar{\delta}_{\mathrm{j}}\right)=\mathrm{q}_{2}[1-\mathrm{H}(\underline{\delta})]\left[\mathrm{L}_{2} \delta_{\mathrm{i}}-\mathrm{c}_{2}-\mathrm{f}\right]+\left[1-\mathrm{q}_{2}+\mathrm{q}_{2} \mathrm{H}(\underline{\delta})\right]\left[\max \left\{\mathrm{L}_{1} \delta_{\mathrm{i}}-\mathrm{c}_{1}, 0\right\}-\mathrm{f}\right] .
$$

Furthermore, it is clear that $\mathrm{Z}^{\mathrm{S}}\left(\underline{\delta}, \bar{\delta}_{\mathrm{j}}\right)=-\mathrm{f}\left[1-\mathrm{q}_{2}+\mathrm{q}_{2} \mathrm{H}(\underline{\delta})\right]<0$, and that $\mathrm{Z}^{\mathrm{S}}\left(\delta_{\mathrm{i}}, \bar{\delta}_{\mathrm{j}}\right)$ is strictly increasing in $\delta_{\mathrm{i}}\left(\right.$ and is independent of $\left.\bar{\delta}_{\mathrm{j}}\right)$. Thus, there is a unique value $\bar{\delta}^{\mathrm{S}} \in\left(\underline{\delta}, \delta_{1}\right)$ such that $\mathrm{Z}^{\mathrm{S}}\left(\bar{\delta}^{\mathrm{S}}, \bar{\delta}^{\mathrm{S}}\right)=0$. Victim i's best response is to file in period 1 if $\delta_{i} \geq \bar{\delta}^{\mathrm{S}}$ and, if $\delta_{\mathrm{i}} \in\left[\underline{\delta}, \bar{\delta}^{\mathrm{S}}\right)$, to wait in period 1 and file in period 2 only if victim $\mathrm{j}$ has already filed suit (and is available to be joined). Thus, for any bandwagon strategy being played by victim j, victim i's best response is to play a bandwagon strategy. This equilibrium is actually in dominant strategies, and is given by $\{\underline{\delta}, \bar{\delta} \mathrm{s}\}$.

Since equations (5) and (8) imply that $\mathrm{Z}^{\mathrm{S}}(\delta, \delta)=\mathrm{Z}^{\mathrm{N}}(\delta, \delta)+\mathrm{q}_{2}[1-\mathrm{H}(\delta)]\left[\mathrm{L}_{2} \delta-\mathrm{c}_{2}-\mathrm{f}\right]$ for $\delta \in$ $\left[\underline{\delta}, \delta_{1}\right)$, it follows that $Z^{\mathrm{S}}\left(\bar{\delta}^{\mathrm{N}}, \bar{\delta}^{\mathrm{N}}\right)=\mathrm{q}_{2}\left[1-\mathrm{H}\left(\bar{\delta}^{\mathrm{N}}\right)\right]\left[\mathrm{L}_{2} \bar{\delta}^{\mathrm{N}}-\mathrm{c}_{2}-\mathrm{f}\right]>0$. Since $\mathrm{Z}^{\mathrm{S}}(\delta, \delta)$ is strictly increasing in $\delta$ and $\mathrm{Z}^{\mathrm{S}}\left(\bar{\delta}^{\mathrm{S}}, \bar{\delta}^{\mathrm{S}}\right)=0$, it follows that $\bar{\delta}^{\mathrm{S}}<\bar{\delta}^{\mathrm{N}}$; that is, more victim types will file in period 1 in the preemptive settlement regime than when no (or only deferred) settlements are possible. On the other hand, there will be no follow-on suits (in equilibrium) in the settlement regime because there will be no non-settled suit to join, while victims with $\delta \in\left[\underline{\delta}, \bar{\delta}^{\mathrm{N}}\right)$ will file follow-on suits when no 
settlement is possible. Thus, in equilibrium, types in $\left[0, \bar{\delta}^{\mathrm{S}}\right)$ will not file while types in $\left[\bar{\delta}^{\mathrm{s}}, \infty\right)$ will file in period 1 and will settle with $\mathrm{D}$ for $\mathrm{s}_{1}^{1}\left(\delta_{\mathrm{i}}, \bar{\delta}^{\mathrm{S}}\right)$ if no other victim filed, or for $\mathrm{L}_{2} \delta_{\mathrm{i}}-\mathrm{c}_{2}$ should two victims have filed. We summarize our results in the following proposition.

Proposition 4. $\left\{\underline{\delta}, \bar{\delta}^{\mathrm{s}}\right\}$ is the unique SBE with preemptive settlement when data is suppressed, where $\bar{\delta}^{\mathrm{S}}$ uniquely satisfies $\mathrm{Z}^{\mathrm{S}}\left(\bar{\delta}^{\mathrm{S}}, \bar{\delta}^{\mathrm{S}}\right)=0$; moreover, $\underline{\delta}<\bar{\delta}^{\mathrm{S}}<\bar{\delta}^{\mathrm{N}}$. In equilibrium:

a) victim $i$ takes the following actions, depending on the level of harm incurred:

i) $\delta_{\mathrm{i}} \in[0, \underline{\delta}) \Rightarrow$ never file;

ii) $\delta_{i} \in\left[\underline{\delta}, \bar{\delta}^{S}\right) \Rightarrow$ wait in period 1 ; file in period 2 only if another victim has filed in period 1 and not settled (in which case, accept any settlement offer of at least $\left.\mathrm{L}_{2} \delta_{\mathrm{i}}-\mathrm{c}_{2}\right)$

iii) $\delta_{\mathrm{i}} \in\left[\bar{\delta}^{\mathrm{s}}, \infty\right) \Rightarrow$ file in period 1 ; if no other victim has filed, accept any settlement offer of at least $s_{1}^{1}\left(\delta_{i}, \bar{\delta}^{s}\right)$;

iv) $\delta_{\mathrm{i}} \in\left[\bar{\delta}^{\mathrm{s}}, \infty\right) \Rightarrow$ file in period 1; if another victim has also filed, accept any settlement offer of at least $\mathrm{L}_{2} \delta_{\mathrm{i}}-\mathrm{c}_{2}$;

b) D makes the following offers if at least one victim has filed in period 1:

i) if only one victim has filed, offer $\mathrm{s}_{1}^{1}\left(\delta_{i}, \bar{\delta}^{\mathrm{s}}\right)$;

ii) if two victims have filed, offer victim $k$ the amount $L_{2} \delta_{k}-c_{2}$.

\section{Preferences Over Preemptive versus Deferred Settlement}

As remarked upon earlier, deferred settlement (wherein settlement can only occur at the end of period 2) is preferred by the defendant to no settlement and plaintiffs are indifferent between deferred and no settlement. We next examine a plaintiff's preferences over preemptive settlement and deferred settlement and show that the plaintiff always (weakly) prefers deferred to preemptive 
settlement and, for some sets of victim types, strictly prefers deferred to preemptive settlement.

Let $\mathrm{V}^{\mathrm{N}}\left(\delta_{\mathrm{i}}\right)$ be plaintiff i's payoff under the equilibrium with no settlement (equivalently, deferred settlement) when her harm is $\delta_{i}$. Similarly, let $\mathrm{V}^{\mathrm{S}}\left(\delta_{\mathrm{i}}\right)$ be plaintiff i's payoff under the equilibrium with preemptive data-suppressing settlement when her harm is $\delta_{\mathrm{i}}$. Then:

and

$$
\mathrm{V}^{\mathrm{N}}\left(\delta_{\mathrm{i}}\right)= \begin{cases}0 & \delta_{\mathrm{i}} \in[0, \underline{\delta}) \\ \mathrm{W}^{\mathrm{N}}\left(\delta_{\mathrm{i}}, \bar{\delta}^{\mathrm{N}}\right) & \delta_{\mathrm{i}} \in\left[\underline{\delta}, \bar{\delta}^{\mathrm{N}}\right) \\ \mathrm{F}^{\mathrm{N}}\left(\delta_{\mathrm{i}}, \bar{\delta}^{\mathrm{N}}\right) & \delta_{\mathrm{i}} \in\left[\bar{\delta}^{\mathrm{N}}, \infty\right)\end{cases}
$$

$$
\mathrm{V}^{\mathrm{S}}\left(\delta_{\mathrm{i}}\right)= \begin{cases}0 & \delta_{\mathrm{i}} \in\left[0, \bar{\delta}^{\mathrm{S}}\right) \\ \mathrm{F}^{\mathrm{S}}\left(\delta_{\mathrm{i}}, \bar{\delta}^{\mathrm{S}}\right) & \delta_{\mathrm{i}} \in\left[\bar{\delta}^{\mathrm{S}}, \infty\right) .\end{cases}
$$

In order to determine whether the plaintiff prefers deferred to preemptive settlement, we examine $\mathrm{V}^{\mathrm{N}}\left(\delta_{\mathrm{i}}\right)-\mathrm{V}^{\mathrm{S}}\left(\delta_{\mathrm{i}}\right)$. Since $\bar{\delta}^{\mathrm{S}}<\bar{\delta}^{\mathrm{N}}$ and $\mathrm{F}^{\mathrm{S}}\left(\delta_{\mathrm{i}}, \bar{\delta}^{\mathrm{S}}\right)=\mathrm{F}^{\mathrm{N}}\left(\delta_{\mathrm{i}}, \bar{\delta}^{\mathrm{N}}\right),{ }^{11}$ then the only places where $\mathrm{V}^{\mathrm{N}}\left(\delta_{\mathrm{i}}\right)$ differs from $\mathrm{V}^{\mathrm{S}}\left(\delta_{\mathrm{i}}\right)$ is on the two intervals $\left[\underline{\delta}, \bar{\delta}^{\mathrm{S}}\right)$ and $\left[\bar{\delta}^{\mathrm{S}}, \bar{\delta}^{\mathrm{N}}\right)$, since the two payoff functions are the same on the other intervals. Furthermore, $\mathrm{V}^{\mathrm{N}}\left(\delta_{\mathrm{i}}\right)-\mathrm{V}^{\mathrm{S}}\left(\delta_{\mathrm{i}}\right)=\mathrm{W}^{\mathrm{N}}\left(\delta_{\mathrm{i}}, \bar{\delta}^{\mathrm{N}}\right)-0>0$ on $\left[\underline{\delta}, \bar{\delta}^{\mathrm{S}}\right)$, while $\mathrm{V}^{\mathrm{N}}\left(\delta_{\mathrm{i}}\right)-$ $\mathrm{V}^{\mathrm{S}}\left(\delta_{\mathrm{i}}\right)=\mathrm{W}^{\mathrm{N}}\left(\delta_{\mathrm{i}}, \bar{\delta}^{\mathrm{N}}\right)-\mathrm{F}^{\mathrm{N}}\left(\delta_{\mathrm{i}}, \bar{\delta}^{\mathrm{N}}\right)>0$ on $\left[\bar{\delta}^{\mathrm{S}}, \bar{\delta}^{\mathrm{N}}\right)$ since waiting is better than filing in the first period (as shown in Section 3) for these types. This is summarized in the following proposition.

\section{Proposition 5.}

(a) Every plaintiff type always weakly prefers deferred settlement to preemptive settlement, and plaintiff types in $\left[\underline{\delta}, \bar{\delta}^{\mathrm{N}}\right)$ strictly prefer deferred settlement to preemptive settlement;

(b) For any distribution $\mathrm{H}$, plaintiffs strictly prefer (in expectation) deferred settlement to preemptive settlement.

Part (b) of the proposition follows immediately from part (a), since the density of $\mathrm{H}$ is assumed to

${ }^{11}$ Recall that $\mathrm{F}^{\mathrm{N}}$ and the reduced form of $\mathrm{F}^{\mathrm{S}}$ are both independent of the other potential victim's strategy. 
be positive everywhere on its support. Thus, in expectation, the plaintiff always strictly prefers deferred settlement to preemptive settlement. Moreover, there is no realized level of harm wherein the plaintiff would strictly prefer preemptive settlement to deferred settlement.

Two other entities would also be of interest: the defendant and society (in the sense of minimizing the expected cost of litigation). Under the uniform distribution, and assuming that $\mathrm{f}<\mathrm{f}_{\mathrm{NQ}}$ (so that $\bar{\delta}^{\mathrm{N}}<\delta_{\mathrm{Q}}$ ), one can show that the aggregate expected filing cost (equivalently, the expected number of suits filed) is higher under preemptive settlement than under deferred settlement; since there are no trials, this means that society prefers deferred to preemptive settlement (see the Technical Appendix for details). Unfortunately, we have no clear result for the defendant's preferences, though we have used computational techniques to explore a set of examples employing various uniform distributions, maintaining the assumption that $\mathrm{f}<\mathrm{f}_{\mathrm{NQ}} \cdot{ }^{12}$ In all of the computed examples, D strictly prefers deferred settlement to preemptive settlement. Essentially, the anticipation of preemptive settlement causes plaintiffs to file more often in period 1 , so much so that the expected number of suits filed is higher when preemptive settlement is possible. Thus, D spends more on settlements and plaintiffs spend more on filing suits under preemptive settlement. Both parties would prefer the bandwagon that arises under deferred settlement to the gold rush that arises under preemptive settlement. However, without the ability to pre-commit not to settle preemptively, we know (see the discussion above of the preemptive settlement offer) that $\mathrm{D}$ will choose to offer a preemptive settlement. Thus, the equilibrium outcome (that is, without pre-commitment to defer) will involve the use of preemptive settlement by D should a lone plaintiff file in period 1 .

\footnotetext{
${ }^{12}$ Note that, since the example uses the uniform distribution, we have assumed a maximum possible value of $\delta$, which is chosen so that it exceeds $\delta_{1}$.
} 


\subsection{Equilibrium Dynamics when Preemptive Settlement Does Not Suppress Data}

We now modify the foregoing in the following way: if one victim files in the first period and settles, and a second victim waits until the second period, then the second victim anticipates winning her case against $\mathrm{D}$ with probability $\mathrm{L}$, where $\mathrm{L}_{2} \geq \mathrm{L} \geq \mathrm{L}_{1}$. Here, the arbitrary level of the likelihood $\mathrm{L}$ allows a number of possible interpretations. If $\mathrm{L}=\mathrm{L}_{2}$, then this might reflect no confidentiality associated with the earlier settlement in conjunction with legal cognizance of "pattern of behavior" (or at least of merging data on legal cause). ${ }^{13}$ If $\mathrm{L}_{2}>\mathrm{L}>\mathrm{L}_{1}$, then $\mathrm{L}$ might reflect the possibility that reliance on data from past cases might be subject to a (currently uncertain) decision by the trial court. Finally, $\mathrm{L}=\mathrm{L}_{1}$ ties the analysis to that of the previous section as it corresponds to data suppression. We use a superscript "A" on the relevant functions and variables to indicate the we are considering the case of preemptive settlement with data availability.

The special treatment for a second-period lone filer (i.e., that D's likelihood of liability is L) who is able to free-ride on the data associated with a first-period filer implies that, once again, the expected payoff to plaintiff $\mathrm{P}_{\mathrm{i}}$ from filing in the first period is the same as under data suppression. This is because the preemptive settlement offer made by a $\mathrm{D}$ to a lone first-period filer will also be the same as that under data suppression: $\mathrm{P}_{\mathrm{i}}$ 's possible outcomes if he rejects D's preemptive offer is that either a second victim sues in period 2 (and therefore the likelihood of liability is $\mathrm{L}_{2}$ ) or no other victim shows up in period 2 (and therefore the likelihood of liability is $\mathrm{L}_{1}$ ). Thus,

$$
\mathrm{F}^{\mathrm{A}}\left(\delta_{\mathrm{i}}, \bar{\delta}_{\mathrm{j}}\right)=\mathrm{q}_{2}[1-\mathrm{H}(\underline{\delta})]\left[\mathrm{L}_{2} \delta_{\mathrm{i}}-\mathrm{c}_{2}-\mathrm{f}\right]+\left[1-\mathrm{q}_{2}+\mathrm{q}_{2} \mathrm{H}(\underline{\delta})\right]\left[\max \left\{\mathrm{L}_{1} \delta_{\mathrm{i}}-\mathrm{c}_{1}, 0\right\}-\mathrm{f}\right] .
$$

That is, $\mathrm{F}^{\mathrm{A}}\left(\delta_{\mathrm{i}}, \bar{\delta}_{\mathrm{j}}\right)=\mathrm{F}^{\mathrm{S}}\left(\delta_{\mathrm{i}}, \bar{\delta}_{\mathrm{j}}\right)=\mathrm{F}^{\mathrm{N}}\left(\delta_{\mathrm{i}}, \bar{\delta}_{\mathrm{j}}\right)$ and, once again, this payoff is independent of $\bar{\delta}_{\mathrm{j}}$.

\footnotetext{
${ }^{13}$ Recall from the background discussion in Section 2 that plaintiffs lawyers may informally coordinate (this is even sometimes organized through interest group discussions and organizations), thereby raising the likelihood that any particular case wins at trial.
} 
There is a significant effect, however, on the value of waiting to file and then proceeding optimally, $\mathrm{W}^{\mathrm{A}}\left(\delta_{\mathrm{i}}, \bar{\delta}_{\mathrm{j}}\right)$, which now must account for the (possibly) increased likelihood of D's liability, $\mathrm{L}$, if $\mathrm{P}_{\mathrm{j}}$ has previously filed and settled in period 1:

$$
\mathrm{W}^{\mathrm{A}}\left(\delta_{\mathrm{i}}, \bar{\delta}_{\mathrm{j}}\right)=\mathrm{q}_{2}\left[1-\mathrm{H}\left(\bar{\delta}_{\mathrm{j}}\right)\right]\left[\max \left\{\mathrm{L}_{\mathrm{i}}-\mathrm{c}_{1}-\mathrm{f}, 0\right\}\right]+\left[1-\mathrm{q}_{2}+\mathrm{q}_{2} \mathrm{H}\left(\bar{\delta}_{\mathrm{j}}\right)\right]\left[\max \left\{\mathrm{L}_{1} \delta_{\mathrm{i}}-\mathrm{c}_{1}-\mathrm{f}, 0\right\}\right]
$$

Let $\mathrm{Z}^{\mathrm{A}}\left(\delta_{\mathrm{i}}, \bar{\delta}_{\mathrm{j}}\right) \equiv \mathrm{F}^{\mathrm{A}}\left(\delta_{\mathrm{i}}, \bar{\delta}_{\mathrm{j}}\right)-\mathrm{W}^{\mathrm{A}}\left(\delta_{\mathrm{i}}, \bar{\delta}_{\mathrm{j}}\right)$ denote the net value of filing in period 1 (net of the value of waiting and then behaving optimally in period 2) in the preemptive settlement regime with no data suppression. Then:

$$
\begin{aligned}
\mathrm{Z}^{\mathrm{A}}\left(\delta_{\mathrm{i}}, \bar{\delta}_{\mathrm{j}}\right)= & \mathrm{q}_{2}[1-\mathrm{H}(\underline{\delta})]\left[\mathrm{L}_{2} \delta_{\mathrm{i}}-\mathrm{c}_{2}-\mathrm{f}\right]+\left[1-\mathrm{q}_{2}+\mathrm{q}_{2} \mathrm{H}(\underline{\delta})\right]\left[\max \left\{\mathrm{L}_{1} \delta_{\mathrm{i}}-\mathrm{c}_{1}, 0\right\}-\mathrm{f}\right] \\
& -\left[\mathrm{q}_{2}\left[1-\mathrm{H}\left(\bar{\delta}_{\mathrm{j}}\right)\right]\left[\max \left\{\mathrm{L} \delta_{\mathrm{i}}-\mathrm{c}_{1}-\mathrm{f}, 0\right\}\right]+\left[1-\mathrm{q}_{2}+\mathrm{q}_{2} \mathrm{H}\left(\bar{\delta}_{\mathrm{j}}\right)\right]\left[\max \left\{\mathrm{L}_{1} \delta_{\mathrm{i}}-\mathrm{c}_{1}-\mathrm{f}, 0\right\}\right]\right] .
\end{aligned}
$$

First, consider $\delta_{\mathrm{i}} \geq \delta_{1}$; then, similar to the earlier analyses, $\mathrm{Z}^{\mathrm{A}}\left(\delta_{\mathrm{i}}, \bar{\delta}_{\mathrm{j}}\right)>0$. That is, any victim $\mathrm{i}$ with damages $\delta_{\mathrm{i}} \geq \delta_{1}$ would strictly prefer to file suit in period 1 . Next, consider $\delta_{\mathrm{i}} \in\left[\underline{\delta}, \delta_{1}\right)$. Then the value of waiting in period 1 is non-negative, since the first term on the right-hand-side of $\mathrm{W}^{\mathrm{A}}\left(\delta_{\mathrm{i}}, \bar{\delta}_{\mathrm{j}}\right)$ is non-negative for these $\delta$-values while the second term is zero. Thus, for $\delta_{i} \in\left[\underline{\delta}, \delta_{1}\right)$, the net gain to filing in period 1 can be written as:

$$
\mathrm{Z}^{\mathrm{A}}\left(\delta_{\mathrm{i}}, \bar{\delta}_{\mathrm{j}}\right)=\mathrm{Z}^{\mathrm{S}}\left(\delta_{\mathrm{i}}, \bar{\delta}_{\mathrm{j}}\right)-\mathrm{q}_{2}\left[1-\mathrm{H}\left(\bar{\delta}_{\mathrm{j}}\right)\right]\left[\max \left\{\mathrm{L}_{\mathrm{i}}-\mathrm{c}_{1}-\mathrm{f}, 0\right\}\right] .
$$

As before, we can use the monotonicity properties of $\mathrm{Z}^{\mathrm{A}}\left(\delta_{\mathrm{i}}, \bar{\delta}_{\mathrm{j}}\right)$ to find the symmetric crossing point, but inspection allows us to find the result more easily. Recall that $Z^{\mathrm{S}}\left(\delta_{\mathrm{i}}, \bar{\delta}_{\mathrm{j}}\right)$ is independent of $\bar{\delta}_{\mathrm{j}}$. Notice what is happening in the second term on the right-hand-side of equation (12). When $\mathrm{L}=\mathrm{L}_{1}$, then $\mathrm{Z}^{\mathrm{A}}\left(\delta_{\mathrm{i}}, \bar{\delta}_{\mathrm{j}}\right)=\mathrm{Z}^{\mathrm{S}}\left(\delta_{\mathrm{i}}, \bar{\delta}_{\mathrm{j}}\right)$, so that the equilibrium symmetric crossing point using equation (11), $\bar{\delta}^{\mathrm{A}}$, is simply $\bar{\delta}^{\text {s; }}$ that is, the waiting set is the same as in the data suppression case, as it must be if $\mathrm{L}=$ $\mathrm{L}_{1}$. Now consider a value of $\mathrm{L}$ slightly larger than $\mathrm{L}_{1}$. Let $\delta_{\mathrm{M}}(\mathrm{L})$ be the marginal type that will pursue a stand-alone case in the second period if $\mathrm{L}$ is the likelihood of winning; that is, $\delta_{\mathrm{M}}(\mathrm{L}) \equiv\left(\mathrm{c}_{1}\right.$ 
$+\mathrm{f}) / \mathrm{L}$. Clearly, $\delta_{\mathrm{M}}\left(\mathrm{L}_{1}\right)=\delta_{1}$, and $\delta_{\mathrm{M}}(\mathrm{L})$ is declining in L but, by continuity, for L only slightly larger than $\mathrm{L}_{1}$ : 1) $\delta_{\mathrm{M}}(\mathrm{L})>\bar{\delta}^{\mathrm{s}}$; and 2) $\mathrm{L} \delta_{\mathrm{M}}(\mathrm{L})-\mathrm{c}_{1}-\mathrm{f}=0$. Thus, as $\mathrm{L}$ becomes larger, so that it causes $\delta_{\mathrm{M}}(\mathrm{L})$ to decline toward $\bar{\delta}^{\text {s }}$ from above, the equilibrium value for the upper bandwagon value found by using equation (12), $\bar{\delta}^{\mathrm{A}}$, will continue to be $\bar{\delta}^{\mathrm{s}}$. Importantly, there is no guarantee that there exists a value of $\mathrm{L} \leq \mathrm{L}_{2}$ such that $\delta_{\mathrm{M}}(\mathrm{L})=\bar{\delta}^{\mathrm{s}}$; if no such value of $\mathrm{L}$ exists, then the equilibrium for the data availability case will always look exactly the same as in the case of data suppression.

If, however, $\mathrm{L}=\mathrm{L}_{2}$ and $\delta_{\mathrm{M}}\left(\mathrm{L}_{2}\right)<\bar{\delta}^{\mathrm{S}}$, then $\mathrm{Z}^{\mathrm{A}}\left(\bar{\delta}^{\mathrm{S}}, \bar{\delta}^{\mathrm{S}}\right)=\mathrm{Z}^{\mathrm{S}}\left(\bar{\delta}^{\mathrm{s}}, \bar{\delta}^{\mathrm{S}}\right)-\mathrm{q}_{2}\left[1-\mathrm{H}\left(\bar{\delta}^{\mathrm{S}}\right)\right]\left[\max \left\{\mathrm{L}_{2} \bar{\delta}^{\mathrm{S}}-\right.\right.$ $\left.\left.\mathrm{c}_{1}-\mathrm{f}, 0\right\}\right]<0$, meaning that $\bar{\delta}^{\mathrm{A}}$ does not equal $\bar{\delta}^{\mathrm{s}}$; in fact, monotonicity of $\mathrm{Z}^{\mathrm{A}}$ means that $\bar{\delta}^{\mathrm{A}}>\bar{\delta}^{\mathrm{s}}$ in this case. Furthermore, when $\mathrm{L}=\mathrm{L}_{2}$ and $\delta_{\mathrm{M}}\left(\mathrm{L}_{2}\right)<\bar{\delta}^{\mathrm{S}}$, it is straightforward to show that $\mathrm{Z}^{\mathrm{A}}\left(\bar{\delta}^{\mathrm{N}}, \bar{\delta}^{\mathrm{N}}\right)=$ $\mathrm{q}_{2}\left[1-\mathrm{H}\left(\bar{\delta}^{\mathrm{N}}\right)\right]\left[\mathrm{c}_{1}-\mathrm{c}_{2}\right]>0$. Therefore, again based on the monotonicity of $\mathrm{Z}^{\mathrm{A}}, \bar{\delta}^{\mathrm{S}}<\bar{\delta}^{\mathrm{A}}<\bar{\delta}^{\mathrm{N}}$. We formalize the results for the case wherein data from a first-period suit which has settled is available to enhance the win probability of a second-period lone filer in the following proposition.

$\underline{\text { Proposition } 6} .\left\{\underline{\delta}, \bar{\delta}^{\mathrm{A}}\right\}$ is the unique SBE with preemptive settlement when data is available.

a) If $\bar{\delta}^{s} \leq\left(c_{1}+f\right) / L_{2}$, then the SBE is exactly the same as described in Proposition 4. In particular, $\bar{\delta}^{\mathrm{A}}=\bar{\delta}^{\mathrm{S}}$.

b) If $\bar{\delta}^{\mathrm{S}}>\left(\mathrm{c}_{1}+\mathrm{f}\right) / \mathrm{L}_{2}$, then $\bar{\delta}^{\mathrm{A}}$ uniquely satisfies $\mathrm{Z}^{\mathrm{A}}\left(\bar{\delta}^{\mathrm{A}}, \bar{\delta}^{\mathrm{A}}\right)=0$; moreover, $\bar{\delta}^{\mathrm{A}} \in\left(\bar{\delta}^{\mathrm{S}}, \bar{\delta}^{\mathrm{N}}\right)$. In equilibrium, victim i takes the following actions, depending on the level of harm:

i) $\delta_{\mathrm{i}} \in[0, \underline{\delta}) \Rightarrow$ never file;

ii) $\delta_{i} \in\left[\underline{\delta},\left(c_{1}+\mathrm{f}\right) / L_{2}\right) \Rightarrow$ wait in period 1 ; file in period 2 only if another victim has

filed in period 1 and not settled (in which case, accept any settlement offer of at least $\mathrm{L}_{2} \delta_{\mathrm{i}}-\mathrm{c}_{2}$ ). 
iii) $\delta_{\mathrm{i}} \in\left[\left(\mathrm{c}_{1}+\mathrm{f}\right) / \mathrm{L}_{2}, \bar{\delta}^{\mathrm{A}}\right) \Rightarrow$ wait in period 1 ; file in period 2 only if another victim has filed in period 1. If the other victim has not settled (resp. settled), accept any settlement offer of at least $L_{2} \delta_{i}-c_{2}\left(\right.$ resp. $\left.L_{2} \delta_{i}-c_{1}\right)$.

iv) $\delta_{\mathrm{i}} \in\left[\bar{\delta}^{\mathrm{A}}, \infty\right) \Rightarrow$ file in period 1 ; if no other victim has filed, accept any settlement offer of at least $\mathrm{s}_{1}^{1}\left(\delta_{\mathrm{i}}, \bar{\delta}^{\mathrm{A}}\right)$;

v) $\delta_{\mathrm{i}} \in\left[\bar{\delta}^{\mathrm{A}}, \infty\right) \Rightarrow$ file in period 1 ; if another victim has also filed, accept any settlement offer of at least $\mathrm{L}_{2} \delta_{\mathrm{i}}-\mathrm{c}_{2}$.

c) In equilibrium, D makes the following offers if at least one victim has filed in period 1:

i) if only one victim has filed in period 1 , offer $\mathrm{s}_{1}^{1}\left(\delta_{\mathrm{i}}, \bar{\delta}^{\mathrm{A}}\right)$; if a victim subsequently files in period 2, offer that victim $\mathrm{L}_{2} \delta_{\mathrm{i}}-\mathrm{c}_{1}$;

ii) if two victims have filed and joined their suits, offer victim $\mathrm{k}$ : $\mathrm{L}_{2} \delta_{\mathrm{k}}-\mathrm{c}_{2}$.

Thus, (in equilibrium) if $\mathrm{L}_{2}$ is not sufficiently greater than $\mathrm{L}_{1}$ (which implies that $\bar{\delta}^{\mathrm{s}} \leq\left(\mathrm{c}_{1}+\mathrm{f}\right.$ )/ $\mathrm{L}_{2}$ ), then equilibrium involves the same gold rush as when data is suppressed and those types in $\left[\underline{\delta}, \bar{\delta}^{\mathrm{A}}\right.$ ) again choose not to file in the second period, even though another plaintiff filed in period 1 (since that plaintiff settled). However, if $\mathrm{L}_{2}$ is sufficiently greater than $\mathrm{L}_{1}$ (that is, $\left.\bar{\delta}^{\mathrm{S}}>\left(\mathrm{c}_{1}+\mathrm{f}\right) / \mathrm{L}_{2}\right)$, then the gold rush is attenuated: types in $\left[\bar{\delta}^{\mathrm{s}}, \bar{\delta}^{\mathrm{A}}\right)$ now do not file in period 1 and wait instead; moreover, even if another victim filed and settled in period 1, types in $\left[\left(c_{1}+f\right) / L_{2}, \bar{\delta}^{A}\right)$ will file in period 2. Notice that it may be impossible for this latter condition to hold, since it is quite possible that $\bar{\delta}^{\mathrm{s}} \leq$ $\left(c_{1}+f\right)$, meaning that there is no value of $L_{2} \leq 1$ such that $\bar{\delta}^{S}>\left(c_{1}+f\right) / L_{2}$.

\section{Equilibrium Dynamics when Some Victims are Unaware of the Source of Harm}

We now reconsider both the basic model and the D-preemptive settlement analysis, except now we assume that the fraction $\rho \in(0,1]$ represents the likelihood that a victim realizes that his or 
her harm is due to the defendant's actions. This fraction is exogenous to the analysis and is fixed at the beginning of period 1 . Since we have previously provided extensive detail on the derivation of the value of waiting or filing in the first period, and the derivation of the symmetric equilibrium, we relegate the detailed descriptions of the analysis to the Appendix. In what follows we provide the essential elements and the relevant summarizing propositions.

\section{Analysis of Partially-Unaware Case when Preemptive Settlement is Not Possible}

First, suppose that no (or only deferred) settlements are possible. A victim who is unaware always "waits" in period 1. However, if a suit is filed in period 1, then those victims who were previously unaware become aware with probability 1 ; however, if no suit is filed in period 1 then unaware victims are assumed to remain unaware in period 2 . We view this as a way to represent the activities of a plaintiff's attorney. If that attorney files the suit for an aware victim, then upon noting that no other suit has been filed, the attorney will endeavor to find out if a second victim exists and to encourage them to file. If no victim comes forward in period 1, then no attorney is triggered to hunt for a second victim, so any unaware victims remain unaware.

Consider the decision problem of a victim who is aware that $\mathrm{D}$ is responsible (but who understands that any other potential victim may be aware only with probability $\rho$ ). By waiting in period 1 , victim $i$ expects to receive a payoff of:

$$
\begin{aligned}
\mathrm{W}_{\rho}^{\mathrm{N}}\left(\delta_{\mathrm{i}}, \bar{\delta}_{\mathrm{j}}\right) \equiv \rho \mathrm{q}_{2}\left[1-\mathrm{H}\left(\bar{\delta}_{\mathrm{j}}\right)\right]\left[\mathrm{L}_{2} \delta_{\mathrm{i}}-\mathrm{c}_{2}-\mathrm{f}\right] & \\
& +\left[1-\mathrm{q}_{2}+(1-\rho) \mathrm{q}_{2}+\rho \mathrm{q}_{2} \mathrm{H}\left(\bar{\delta}_{\mathrm{j}}\right)\right]\left[\max \left\{\mathrm{L}_{1} \delta_{\mathrm{i}}-\mathrm{c}_{1}-\mathrm{f}, 0\right\}\right] .
\end{aligned}
$$

Now suppose that victim i files suit in period 1 . Then he expects to receive a payoff of:

$$
\begin{aligned}
\mathrm{F}_{\rho}^{\mathrm{N}}\left(\delta_{\mathrm{i}}, \bar{\delta}_{\mathrm{j}}\right) \equiv \rho \mathrm{q}_{2}\left[1-\mathrm{H}\left(\bar{\delta}_{\mathrm{j}}\right)\right]\left[\mathrm{L}_{2} \delta_{\mathrm{i}}-\mathrm{c}_{2}-\mathrm{f}\right] & \\
& +\left\{(1-\rho) \mathrm{q}_{2}\left[1-\mathrm{H}\left(\bar{\delta}_{\mathrm{j}}\right)\right]+\mathrm{q}_{2}\left[\mathrm{H}\left(\bar{\delta}_{\mathrm{j}}\right)-\mathrm{H}(\underline{\delta})\right]\right\}\left[\mathrm{L}_{2} \delta_{\mathrm{i}}-\mathrm{c}_{2}-\mathrm{f}\right]
\end{aligned}
$$




$$
+\left[1-\mathrm{q}_{2}+\mathrm{q}_{2} \mathrm{H}(\underline{\delta})\right]\left[\max \left\{\mathrm{L}_{1} \delta_{\mathrm{i}}-\mathrm{c}_{1}, 0\right\}-\mathrm{f}\right] .
$$

Upon collecting terms, we note that $\mathrm{F}_{\mathrm{p}}^{\mathrm{N}}\left(\delta_{\mathrm{i}}, \bar{\delta}_{\mathrm{j}}\right)$ is the same as $\mathrm{F}^{\mathrm{N}}\left(\delta_{\mathrm{i}}, \bar{\delta}_{\mathrm{j}}\right)$ for all $\rho$; the value of filing suit (for an aware victim) is independent of the likelihood that the other victim is aware. That is:

$$
\mathrm{F}_{\rho}^{\mathrm{N}}\left(\delta_{\mathrm{i}}, \bar{\delta}_{\mathrm{j}}\right) \equiv \mathrm{q}_{2}[1-\mathrm{H}(\underline{\delta})]\left[\mathrm{L}_{2} \delta_{\mathrm{i}}-\mathrm{c}_{2}-\mathrm{f}\right]+\left[1-\mathrm{q}_{2}+\mathrm{q}_{2} \mathrm{H}(\underline{\delta})\right]\left[\max \left\{\mathrm{L}_{1} \delta_{\mathrm{i}}-\mathrm{c}_{1}, 0\right\}-\mathrm{f}\right] .
$$

Let $Z_{\rho}^{\mathrm{N}}\left(\delta_{\mathrm{i}}, \bar{\delta}_{\mathrm{j}}\right) \equiv \mathrm{F}_{\mathrm{\rho}}^{\mathrm{N}}\left(\delta_{\mathrm{i}}, \bar{\delta}_{\mathrm{j}}\right)-\mathrm{W}_{\rho}^{\mathrm{N}}\left(\delta_{\mathrm{i}}, \bar{\delta}_{\mathrm{j}}\right)$ denote the net value of filing in period 1 (net of the value of waiting and then behaving optimally in period 2), for $\rho \in(0,1]$. The SBE period 1 filing threshold is given by $\bar{\delta}_{\rho}^{\mathrm{N}} \in\left(\underline{\delta}, \delta_{1}\right)$ such that $\mathrm{Z}_{\rho}^{\mathrm{N}}\left(\bar{\delta}_{\rho}^{\mathrm{N}}, \bar{\delta}_{\rho}^{\mathrm{N}}\right)=0$. Since $\mathrm{F}_{\rho}^{\mathrm{N}}\left(\delta_{\mathrm{i}}, \bar{\delta}_{\mathrm{j}}\right)$ is independent of $\rho$ and $\mathrm{W}_{\rho}^{\mathrm{N}}\left(\delta_{\mathrm{i}}, \bar{\delta}_{\mathrm{j}}\right)$ is increasing in $\rho$, it follows that $\bar{\delta}_{\rho}^{\mathrm{N}}$ is an increasing function of $\rho$ which converges to $\bar{\delta}^{\mathrm{N}}$ as $\rho \rightarrow 1$. Moreover, since $\mathrm{F}_{\rho}^{\mathrm{N}}\left(\delta_{\mathrm{i}}, \bar{\delta}_{\mathrm{j}}\right)=\mathrm{F}^{\mathrm{N}}\left(\delta_{\mathrm{i}}, \bar{\delta}_{\mathrm{j}}\right)$ and, as seen in Section 4.1 above, $\mathrm{F}^{\mathrm{N}}\left(\delta_{\mathrm{i}}, \bar{\delta}_{\mathrm{j}}\right)=$ $\mathrm{F}^{\mathrm{S}}\left(\delta_{\mathrm{i}}, \bar{\delta}_{\mathrm{j}}\right)$, it follows that $\bar{\delta}_{\rho}^{\mathrm{N}}$ converges to $\bar{\delta}^{\mathrm{S}}$ as $\rho \rightarrow 0$. Thus, the "window of waiting" is a set intermediate between the fully-aware preemptive settlement waiting-set and the fully-aware deferred settlement waiting-set of the basic model. We summarize our results in the following proposition. ${ }^{14}$ Proposition 7. $\left\{\underline{\delta}, \bar{\delta}_{\rho}^{\mathrm{N}}\right\}$ is the unique SBE without preemptive settlement but with partially unaware victims, where $\bar{\delta}_{\rho}^{\mathrm{N}}$ uniquely satisfies $\mathrm{Z}_{\rho}^{\mathrm{N}}\left(\bar{\delta}_{\rho}^{\mathrm{N}}, \bar{\delta}_{\rho}^{\mathrm{N}}\right)=0$; moreover, for $\rho \in(0,1), \bar{\delta}_{\rho}^{\mathrm{N}} \in\left(\bar{\delta}^{\mathrm{S}}, \bar{\delta}^{\mathrm{N}}\right)$. In equilibrium:

a) a victim $\mathrm{i}$ who is aware in period 1 takes the following actions, depending on the level of harm incurred:

i) $\delta_{\mathrm{i}} \in[0, \underline{\delta}) \Rightarrow$ never file;

ii) $\delta_{\mathrm{i}} \in\left[\underline{\delta}, \bar{\delta}_{\rho}^{\mathrm{N}}\right) \Rightarrow$ wait in period 1 , file in period 2 only if another victim has filed in period 1;

\footnotetext{
${ }^{14}$ The cutoff for $\mathrm{f}$ used in part of this proposition, $\mathrm{f}_{\mathrm{NQp}}$, is the parallel notion for the relationship between $\bar{\delta}_{\rho}^{\mathrm{N}}$ and $\delta_{\mathrm{Q}}$ as $\mathrm{f}_{\mathrm{NQ}}$ is for the relationship between $\bar{\delta}^{\mathrm{N}}$ and $\delta_{\mathrm{Q}}$; see the discussion of the earlier notion in Section 3.
} 
iii) (1) $\mathrm{f}<\mathrm{f}_{\mathrm{NQ} \rho}$ and $\delta_{\mathrm{i}} \in\left[\bar{\delta}_{\rho}^{\mathrm{N}}, \delta_{\mathrm{Q}}\right) \Rightarrow$ file in period 1 , drop in period 2 only if no other victim filed in period 1 or 2 ;

(2) $\mathrm{f}<\mathrm{f}_{\mathrm{NQ} \rho}$ and $\delta_{\mathrm{i}} \in\left[\delta_{\mathrm{Q}}, \infty\right) \Rightarrow$ file in period 1, continue to sue in period 2;

(3) $\mathrm{f} \geq \mathrm{f}_{\mathrm{NQ} \rho}$ and $\delta_{\mathrm{i}} \in\left[\bar{\delta}_{\rho}^{\mathrm{N}}, \infty\right) \Rightarrow$ file in period 1 , continue to sue in period 2 .

b) a victim $\mathrm{i}$ who is unaware in period 1 "waits" in period 1 and files in period 2 only if $\delta_{\mathrm{i}}$ $\geq \underline{\delta}$ and another victim has filed in period 1 .

\section{Analysis of Partially-Unaware Case when Preemptive Settlement is Possible}

Now suppose it is common knowledge that, at every stage, D can offer a settlement to any plaintiff who has filed suit. As before, suppose that (at the point of bargaining) damages are common knowledge and that D need only offer what that plaintiff could expect from continuing with her suit. In addition to data suppression, however, now first-period settlements involve a promise not to alert any victims who are unaware of the defendant's involvement in their harm. As in Section 4.1, if only one victim (say, victim i) files in period 1 , then $\mathrm{D}$ need only offer him his expected continuation value (from not settling), which is computed below. This continuation value will depend on $\rho$; we denote this amount by $s_{1 \rho}^{1}\left(\delta_{i}, \bar{\delta}_{j}\right)$.

$$
\begin{aligned}
\mathrm{s}_{1 \rho}^{1}\left(\delta_{\mathrm{i}}, \bar{\delta}_{\mathrm{j}}\right) \equiv\left\{\left[\mathrm{q}_{2}(1-\rho)\left[1-\mathrm{H}\left(\bar{\delta}_{\mathrm{j}}\right)\right]+\mathrm{q}_{2}\left[\mathrm{H}\left(\bar{\delta}_{\mathrm{j}}\right)-\mathrm{H}(\underline{\delta})\right]\right] /\left[1-\mathrm{q}_{2}+\mathrm{q}_{2}(1-\rho)+\rho \mathrm{q}_{2} \mathrm{H}\left(\bar{\delta}_{\mathrm{j}}\right)\right]\right\}\left[\mathrm{L}_{2} \delta_{\mathrm{i}}-\mathrm{c}_{2}\right] \\
+\left\{\left[1-\mathrm{q}_{2}+\mathrm{q}_{2} \mathrm{H}(\underline{\delta})\right] /\left[1-\mathrm{q}_{2}+\mathrm{q}_{2}(1-\rho)+\rho \mathrm{q}_{2} \mathrm{H}\left(\bar{\delta}_{\mathrm{j}}\right)\right]\right\}\left[\max \left\{\mathrm{L}_{1} \delta_{\mathrm{i}}-\mathrm{c}_{1}, 0\right\}\right] .(15)
\end{aligned}
$$

$\mathrm{P}_{\mathrm{i}}$ 's expected payoff from waiting in period 1 is:

$$
\mathrm{W}_{\rho}^{\mathrm{S}}\left(\delta_{\mathrm{i}}, \bar{\delta}_{\mathrm{j}}\right)=\max \left\{\mathrm{L}_{1} \delta_{\mathrm{i}}-\mathrm{c}_{1}-\mathrm{f}, 0\right\} .
$$

Note that $\mathrm{W}_{\rho}^{\mathrm{S}}\left(\delta_{\mathrm{i}}, \bar{\delta}_{\mathrm{j}}\right)=\mathrm{W}^{\mathrm{S}}\left(\delta_{\mathrm{i}}, \bar{\delta}_{\mathrm{j}}\right)$. On the other hand, $\mathrm{P}_{\mathrm{i}}$ 's expected payoff if he files in period 1 is:

$$
\mathrm{F}_{\rho}^{\mathrm{S}}\left(\delta_{\mathrm{i}}, \bar{\delta}_{\mathrm{j}}\right)=\rho \mathrm{q}_{2}\left[1-\mathrm{H}\left(\bar{\delta}_{\mathrm{j}}\right)\right]\left[\mathrm{L}_{2} \delta_{\mathrm{i}}-\mathrm{c}_{2}-\mathrm{f}\right]+\left[1-\mathrm{q}_{2}+\mathrm{q}_{2}(1-\rho)+\rho \mathrm{q}_{2} \mathrm{H}\left(\bar{\delta}_{\mathrm{j}}\right)\right]\left[\mathrm{s}_{1 \rho}^{1}\left(\delta_{\mathrm{i}}, \bar{\delta}_{\mathrm{j}}\right)-\mathrm{f}\right]
$$




$$
=\mathrm{q}_{2}[1-\mathrm{H}(\underline{\delta})]\left[\mathrm{L}_{2} \delta_{\mathrm{i}}-\mathrm{c}_{2}-\mathrm{f}\right]+\left[1-\mathrm{q}_{2}+\mathrm{q}_{2} \mathrm{H}(\underline{\delta})\right]\left[\max \left\{\mathrm{L}_{1} \delta_{\mathrm{i}}-\mathrm{c}_{1}, 0\right\}-\mathrm{f}\right] .
$$

Thus, $\mathrm{F}_{\rho}^{\mathrm{S}}\left(\delta_{\mathrm{i}}, \bar{\delta}_{\mathrm{j}}\right)$ is exactly the same as $\mathrm{F}^{\mathrm{S}}\left(\delta_{\mathrm{i}}, \bar{\delta}_{\mathrm{j}}\right)\left(\right.$ and $\mathrm{F}_{\mathrm{\rho}}^{\mathrm{N}}\left(\delta_{\mathrm{i}}, \bar{\delta}_{\mathrm{j}}\right)$ and $\left.\mathrm{F}^{\mathrm{N}}\left(\delta_{\mathrm{i}}, \bar{\delta}_{\mathrm{j}}\right)\right)$. The value of filing in period 1 is independent of $\rho$ and is the same whether or not settlement is deferred. All of these expressions are equal because of the assumption that $\mathrm{D}$ needs only to offer $\mathrm{P}_{\mathrm{i}}$ 's continuation value in settlement. Since $\mathrm{F}_{\rho}^{\mathrm{S}}\left(\delta_{\mathrm{i}}, \bar{\delta}_{\mathrm{j}}\right)$ and $\mathrm{W}_{\rho}^{\mathrm{S}}\left(\delta_{\mathrm{i}}, \bar{\delta}_{\mathrm{j}}\right)$ are independent of $\rho$, their difference $\mathrm{Z}_{\rho}^{\mathrm{S}}\left(\delta_{\mathrm{i}}, \bar{\delta}_{\mathrm{j}}\right) \equiv$ $\mathrm{F}_{\rho}^{\mathrm{S}}\left(\delta_{\mathrm{i}}, \bar{\delta}_{\mathrm{j}}\right)-\mathrm{W}_{\rho}^{\mathrm{S}}\left(\delta_{\mathrm{i}}, \bar{\delta}_{\mathrm{j}}\right)$ is also independent of $\rho$, as is the solution $\bar{\delta}_{\rho}^{\mathrm{S}}$ to the equation $Z_{\rho}^{\mathrm{S}}(\delta, \delta)=0$. That is, when settlement is possible at every stage, the period 1 filing threshold is $\bar{\delta}_{\rho}^{\mathrm{S}}=\bar{\delta}^{\mathrm{S}}$ for all $\rho$.

Since $\bar{\delta}_{\rho}^{\mathrm{S}}$ is independent of $\rho$, it is clear that the settlement from filing alone in period 1, $\mathrm{s}_{1 \rho}^{1}\left(\delta_{\mathrm{i}}, \bar{\delta}_{\rho}^{\mathrm{S}}\right)$, is decreasing in $\rho$. Alternatively put, when settlement is possible at every stage, $\mathrm{P}_{\mathrm{i}}$ expects to receive a higher settlement offer the lower is the likelihood $\rho$ that $\mathrm{P}_{\mathrm{j}}$ is aware; this is because there is likely to be a higher fraction of $\mathrm{P}_{\mathrm{j}} \mathrm{s}$ with viable suits among those waiting in period 1 (and $\mathrm{P}_{\mathrm{i}}$ can bring on these follow-on suits by declining to settle). In settling, $\mathrm{P}_{\mathrm{i}}$ (or his attorney) agrees not to alert any victim who is unaware. Thus, $\mathrm{P}_{\mathrm{i}}$ capitalizes on $\mathrm{P}_{\mathrm{j}}$ 's lack of awareness by extracting a higher settlement offer from D. These results are formalized in the following proposition.

Proposition $8 .\left\{\underline{\delta}, \bar{\delta}_{\rho}^{\mathrm{S}}\right\}$ is the unique SBE with preemptive settlement and partially unaware victims, where $\bar{\delta}_{\rho}^{\mathrm{S}}$ uniquely satisfies $Z_{\rho}^{\mathrm{S}}\left(\bar{\delta}_{\rho}^{\mathrm{s}}, \bar{\delta}_{\rho}^{\mathrm{S}}\right)=0$; moreover, $\bar{\delta}_{\rho}^{\mathrm{S}}=\bar{\delta}^{\mathrm{s}}$ for all $\rho$. In equilibrium:

a) an aware victim $i$ takes the following actions, depending on the level of harm incurred:

i) $\delta_{\mathrm{i}} \in[0, \underline{\delta}) \Rightarrow$ never file;

(ii) $\delta_{\mathrm{i}} \in\left[\underline{\delta}, \bar{\delta}^{\mathrm{S}}\right) \Rightarrow$ wait in period 1 ; file in period 2 only if another victim has filed in period 1 and not settled (in which case, accept any settlement offer of at least $\left.\mathrm{L}_{2} \delta_{\mathrm{i}}-\mathrm{c}_{2}\right)$

iii) $\delta_{\mathrm{i}} \in\left[\bar{\delta}^{\mathrm{s}}, \infty\right) \Rightarrow$ file in period 1 ; if no other victim has filed, accept any settlement 
offer of at least $s_{1 \rho}^{1}\left(\delta_{i}, \bar{\delta}^{S}\right)$; this settlement is decreasing in $\rho$.

iv) $\delta_{\mathrm{i}} \in\left[\bar{\delta}^{\mathrm{S}}, \infty\right) \Rightarrow$ file in period 1; if another victim has also filed, accept any settlement offer of at least $\mathrm{L}_{2} \delta_{\mathrm{i}}-\mathrm{c}_{2}$;

b) D makes the following offers if at least one victim has filed in period 1:

i) if only one victim has filed, offer $s_{1 \rho}^{1}\left(\delta_{i}, \bar{\delta}^{s}\right)$;

ii) if two victims have filed, offer victim $k$ the amount $L_{2} \delta_{k}-c_{2}$.

\section{Preferences Over Preemptive versus Deferred Settlement}

It is straightforward to show that, as earlier, potential victims strictly prefer deferred to preemptive settlement. Now, however, it is possible to show that for sufficiently small (but positive) levels of $\rho$, the defendant strictly prefers preemptive settlement; the details are provided in the Technical Appendix. This is because when $\rho$ is small, D's option to make a preemptive settlement results in a very low likelihood of a gold rush, while in the rare event of a lone suit filed in period 1, settlement can suppress any viable follow-on suit which would otherwise be filed. Recall that earlier, relying on computational means, we found that there were conditions wherein the defendant's preferences over the two alternatives were aligned with those of the plaintiffs. However, for small enough $\rho$, the parties' preferences will conflict.

\section{Summary, Implications and Potential Extensions}

We model the formation of a joint suit as a game of endogenous timing. There is an equilibrium in "bandwagon" strategies wherein a victim with sufficiently high damages files in period 1, a victim with intermediate damages waits in period 1 and files in period 2 only if another victim has filed and is available to be joined, and a victim with sufficiently low damages never files suit. When settlements are not permitted or if settlements are deferred, then suits are filed in both 
periods along the equilibrium path. When preemptive settlements are allowed and the defendant only needs to offer a plaintiff's continuation value to induce settlement, then the defendant cannot resist the temptation to settle in every period. In this case, there is never another plaintiff to be joined in period 2 and hence no value to waiting due to data suppression. Thus, the bandwagon is more of a "gold rush" when preemptive settlement is allowed.

Potential plaintiffs strictly prefer deferred settlement to preemptive settlement on an ex ante basis in both the fully-aware and the partially-unaware cases. In the fully-aware analysis we find (via extensive numerical computation using a uniform distribution of damages) that the defendant can also strictly prefer deferred settlement to preemptive settlement, and thus deferred settlement can be Pareto-superior to preemptive settlement. If the defendant could make a credible commitment ex ante not to engage in preemptive settlement, then plaintiffs would not rush to file in period 1 , but would rather follow the more deliberate two-period filing process. Under the uniform distribution, the defendant would face a lower ex ante expected number of suits under deferred settlement; thus the defendant would save on settlements while the plaintiffs would save on filing costs. A commitment mechanism would be necessary, however, since this policy would suffer from time inconsistency; once first-period filing had occurred, the defendant would have an incentive to settle preemptively with a lone, early filer in order to discourage further suits that would be filed in period 2 if a previous plaintiff were available to be joined. In contrast, we find that if the fraction of aware victims is sufficiently low then (independent of the distribution, $H$ ) the defendant will strictly prefer having the option to make a preemptive settlement offer.

We further examined the effect of allowing preemptive settlement by considering what happens if second-period lone filers can free-ride on the data associated with a first-period lone filer 
who settled. We showed that only if the gain in the likelihood of liability that data-sharing might yield was sufficiently high would the equilibrium shift from one of a gold rush to one wherein there were some types that would wait and then file later (if a victim had filed previously, even if that victim had settled with the defendant). Thus, preemptive settlement has a very strong effect, and second-period filing will only occur (if at all) when the data from the first-period filer's case is available and the plaintiff's gain from having that data available is sufficiently great (and that bar might not be possible to meet). This suggests that if society wishes to moderate the gold rush effect that preemptive settlement induces, it must allow follow-on cases concerned with related harms to have access to this sort of data.

This is not necessarily how the law currently operates. Confidential settlement agreements (see Daughety and Reinganum, 1999, 2000) limit parties and their lawyers from sharing information with those who are not a party to the agreement, meaning not only other potential litigants, but public health authorities as well. One particularly well-know example involved leakage into the groundwater of carcinogenic chemicals from a Xerox plant near Webster, New York; the leakage contaminated some of the nearby wells (see Weiser, 1989, for details on this case). Xerox informed local residents about the leak but assured them that there were no long-term health risks. Two families with members who suffered health problems, including one who contracted a very rare form of cancer, sued Xerox. The confidential settlement (sealed by a court, but believed to amount to $\$ 4.75$ million) that was concluded between Xerox and the two families cut out the local public health authorities as well as the neighbors, who apparently woke up one day to see moving vans moving the two families out of their homes.

Finally, when preemptive settlement is allowed and victims are partially unaware, the first 
victim/attorney pair can be induced to eschew outreach (and thus, to leave unaware victims in the dark) in exchange for a settlement. Since the likelihood of a follow-on suit (that can be triggered by not settling) is an increasing function of the fraction of unaware victims, the settlement offered to the first victim/attorney pair is also an increasing function of the fraction of unaware victims. Thus, the first victim/attorney pair receives a higher settlement offer in exchange for "selling out" a victim who is more likely to be unaware that the defendant is responsible for her harm.

\section{Potential Extensions}

There are a number of possible extensions of this model. In particular, one could envision a larger number of potential plaintiffs. Although it is possible to extend this model directly, one would now want to allow as many periods as there are plaintiffs in order to allow the full dynamics to evolve. This would become quite combinatoric as there would be thresholds for filing that depend on exactly how many previous cases have been filed. Alternatively, consider the setting raised in Footnote 7, where two towns, each sited near a chain's gas station, suffer damages to their water supply due to leaks from the underground gasoline storage tanks at the service stations. A direct application of our model would entail letting $\delta_{\mathrm{k}}$ be the sum of group (town) k's individual damages. This then suggests a further extension: one would like to allow for damages for each victim (or victim group) to be drawn from different distributions, thereby requiring characterization of an asymmetric bandwagon equilibrium. Another worthwhile modification would be to model explicitly conflicts of interest between a victim and his or her attorney and perhaps conflicts of interest among plaintiffs. Finally, alternative game forms that differ in terms of the information structure (e.g., asymmetric information at the time of bargaining) and the bargaining solution (e.g., the Nash bargaining solution) would provide additional insights and robustness checks. 


\section{References}

Che, Yeon-Koo. "Equilibrium Formation of Class Action Suits," Journal of Public Economics 62 (1996), 339-361.

Che, Yeon-Koo. “The Economics of Collective Negotiation in Pretrial Bargaining,” International Economic Review 43 (2002), 549-575.

Che, Yeon-Koo and Kathryn E. Spier, "Exploiting Plaintiffs through Settlement: Divide and Conquer," Journal of Institutional and Theoretical Economics 164 (2008), 4-23.

Daughety, Andrew F. and Jennifer F. Reinganum, "Hush Money," RAND Journal of Economics 30 (1999), 661-678.

Daughety, Andrew F. and Jennifer F. Reinganum, "Informational Externalities in Settlement Bargaining: Confidentiality and Correlated Culpability," RAND Journal of Economics 33 (2002), 587-604.

Daughety, Andrew F. and Jennifer F. Reinganum, "Population-Based Liability Determination, Mass Torts, and the Incentives for Suit, Settlement, and Trial," Journal of Law, Economics, and Organization, forthcoming 2010; also available at http://jleo.oxfordjournals.org/papbyrecent.dtl.

Deffains, Bruno and Langlais, Eric. "Informational Externalities and Information Sharing in Class Action Suits" (February 4, 2009). Available at SSRN: http://ssrn.com/abstract=900529

Erichson, Howard M., "Informal Aggregation: Procedural and Ethical Implications of Coordination Among Counsel in Related Lawsuits," Duke Law Journal 50 (2000), 381-471.

Farrell, Joseph and Garth Saloner. "Standardization, Compatibility, and Innovation," RAND Journal of Economics 16 (1985), 70-83.

Kim, Jeong-Yoo. "Filing a Nuisance Claim to Induce Successive Lawsuits," Economics Review 6 (2004), 208-216.

Marceau, Nicolas and Steeve Mongrain, "Damage Averaging and the Formation of Class Action Suits," International Review of Law and Economics 23 (2003), 63-74.

Nagareda, Richard A. Mass Torts in a World of Settlement. Chicago: The University of Chicago Press, 2007.

Weiser, B. "Secret Settlement Shrouds Health Impact of Xerox Plant Leak," The Washington Post, March 13, 1989, A01. 
Appendix

The Basic Model with Arbitrarily Many Periods

Instead of 2 periods, suppose there are arbitrarily many periods. We show that there exists a Nash Equilibrium in bandwagon strategies that involves the same threshold values as in the 2period case.

First, we need to modify slightly the definition of a bandwagon strategy to account for the fact that there are more than 2 periods. Part (b) of the definition becomes:

(b) if $\underline{\delta}_{\mathrm{j}} \leq \delta_{\mathrm{j}}<\bar{\delta}_{\mathrm{j}}$, then victim $\mathrm{j}$ waits in period 1 and files suit in any subsequent period only if another victim has already filed suit (and is available to be joined).

A symmetric bandwagon equilibrium is, as before, a bandwagon strategy $\{\underline{\delta}, \bar{\delta}\}$, with $\bar{\delta} \geq \underline{\delta}$, that is a mutual best response. Moreover, the critical damages level below which a victim will never file remains $\underline{\delta} \equiv\left(\mathrm{c}_{2}+\mathrm{f}\right) / \mathrm{L}_{2}$.

Suppose that victim j employs a bandwagon strategy $\left\{\underline{\delta}, \bar{\delta}_{j}\right\}$. We will characterize victim i's best response, beginning with period 2. If victim i filed suit in period 1, then he has no further action to take. Suppose that victim $i$ did not file suit in period 1 . If victim $j$ filed suit in period 1 , then victim $\mathrm{j}$ has no further action to take and nothing will change in the future; thus victim $\mathrm{i}$ will file suit in period 2 (following victim $\mathrm{j}$ ) if $\mathrm{L}_{2} \delta_{\mathrm{i}}-\mathrm{c}_{2}-\mathrm{f} \geq 0$ (that is, if $\delta_{\mathrm{i}} \geq \underline{\delta}$ ) and otherwise he will never file.

Now suppose that neither victim filed in period 1 . If victim $\mathrm{j}$ did not file suit in period 1 , then victim $\mathrm{i}$ does not expect victim $\mathrm{j}$ to file suit in period 2; moreover, unless victim $\mathrm{i}$ files suit he does not expect victim $\mathrm{j}$ to file suit in any subsequent period. This is because either victim $\mathrm{j}$ does not exist or, if she does exist, she has $\delta_{\mathrm{j}}<\bar{\delta}_{\mathrm{j}}$; the combined probability of these two events is $1-\mathrm{q}_{2}$ $+\mathrm{q}_{2} \mathrm{H}\left(\bar{\delta}_{\mathrm{j}}\right)$. Note that if victim $\mathrm{i}$ waits in period 2 , he expects that nothing will change in any subsequent period, so his decision is really between filing in period 2 or never filing. If victim i files suit in period 2 , then he expects victim $\mathrm{j}$ to follow him in period 3 with probability $\mathrm{q}_{2}\left\{\left[\mathrm{H}\left(\bar{\delta}_{\mathrm{j}}\right)-\right.\right.$ $\left.\mathrm{H}(\underline{\delta})] /\left[1-\mathrm{q}_{2}+\mathrm{q}_{2} \mathrm{H}\left(\bar{\delta}_{\mathrm{j}}\right)\right]\right\}$; on the other hand, if victim $\mathrm{j}$ does not exist or has $\delta_{\mathrm{j}}<\underline{\delta}$, then she will not follow victim $\mathrm{i}$ in period 3 even if he files in period 2; this event has probability $\left\{\left[1-\mathrm{q}_{2}+\mathrm{q}_{2} \mathrm{H}(\underline{\delta})\right] /[1\right.$ $\left.\left.-\mathrm{q}_{2}+\mathrm{q}_{2} \mathrm{H}\left(\bar{\delta}_{\mathrm{j}}\right)\right]\right\}$. If he is not joined in period 3 by victim $\mathrm{j}$, then $\mathrm{P}_{\mathrm{i}}$ must re-assess his position and decide whether to drop or proceed with his suit. Thus, victim i expects the following payoff, denoted $\mathrm{z}^{\mathrm{N}}\left(\delta_{\mathrm{i}}, \bar{\delta}_{\mathrm{j}}\right)$, if he files in period 2 (following a history in which neither victim filed in period 1):

$$
\begin{aligned}
\mathrm{z}^{\mathrm{N}}\left(\delta_{\mathrm{i}}, \bar{\delta}_{\mathrm{j}}\right) \equiv \mathrm{q}_{2}\left\{\left[\mathrm{H}\left(\bar{\delta}_{\mathrm{j}}\right)-\mathrm{H}(\underline{\delta})\right] /\left[1-\mathrm{q}_{2}+\mathrm{q}_{2} \mathrm{H}\left(\bar{\delta}_{\mathrm{j}}\right)\right]\right\}\left[\mathrm{L}_{2} \delta_{\mathrm{i}}-\mathrm{c}_{2}-\mathrm{f}\right] \\
+\left\{\left[1-\mathrm{q}_{2}+\mathrm{q}_{2} \mathrm{H}(\underline{\delta})\right] /\left[1-\mathrm{q}_{2}+\mathrm{q}_{2} \mathrm{H}\left(\bar{\delta}_{\mathrm{j}}\right)\right]\right\}\left[\max \left\{\mathrm{L}_{1} \delta_{\mathrm{i}}-\mathrm{c}_{1}, 0\right\}-\mathrm{f}\right] .
\end{aligned}
$$

We now characterize a threshold value of $\delta_{\mathrm{i}}$, denoted $\psi\left(\bar{\delta}_{\mathrm{j}}\right)$, with the property that it is optimal for victim $i$ to file suit in period 2 (following a history in which neither victim filed in period 1) only 
if $\delta_{\mathrm{i}} \geq \psi\left(\bar{\delta}_{\mathrm{j}}\right)$. First, consider the case of $\bar{\delta}_{\mathrm{j}}=\underline{\delta}$; then $\mathrm{z}^{\mathrm{N}}\left(\delta_{\mathrm{i}}, \underline{\delta}\right)(>,=,<) 0$ as $\delta_{\mathrm{i}}(>,=,<) \delta_{1}$ and thus $\psi\left(\bar{\delta}_{\mathrm{j}}\right)$ $=\delta_{1}$. Next, consider $\bar{\delta}_{\mathrm{j}}>\underline{\delta}$ : the facts that: (a) $\mathrm{z}^{\mathrm{N}}\left(\underline{\delta} ; \bar{\delta}_{\mathrm{j}}\right)=-\mathrm{f}\left\{\left[1-\mathrm{q}_{2}+\mathrm{q}_{2} \mathrm{H}(\underline{\delta})\right] /\left[1-\mathrm{q}_{2}+\mathrm{q}_{2} \mathrm{H}\left(\bar{\delta}_{\mathrm{j}}\right)\right]\right\}<0$; (b) $\mathrm{z}^{\mathrm{N}}\left(\delta_{1} ; \bar{\delta}_{\mathrm{j}}\right)>0$; and $(\mathrm{c}) \mathrm{z}^{\mathrm{N}}\left(\delta_{\mathrm{i}}, \bar{\delta}_{\mathrm{j}}\right)$ is strictly increasing in its first argument, jointly imply that there exists a unique value of $\delta_{\mathrm{i}} \in\left[\underline{\delta}, \delta_{1}\right)$, denoted $\psi\left(\bar{\delta}_{\mathrm{j}}\right)$, at which $\mathrm{z}^{\mathrm{N}}\left(\psi\left(\bar{\delta}_{\mathrm{j}}\right) ; \bar{\delta}_{\mathrm{j}}\right)=0$. Moreover, it is optimal for victim i to file suit in period 2 (follow a history in which neither victim filed in period 1 ) only if $\delta_{\mathrm{i}} \geq \psi\left(\bar{\delta}_{\mathrm{j}}\right)$.

We can now write victim i's expected payoff from waiting in period 1 , denoted $\mho^{\mathrm{N}}\left(\delta_{\mathrm{i}}, \bar{\delta}_{\mathrm{j}}\right)$ to indicate the many-period case, as follows (again, we need only consider values of $\delta_{\mathrm{i}} \geq \underline{\delta}$ ):

$$
\begin{gathered}
\mathscr{V}^{\mathrm{N}}\left(\delta_{\mathrm{i}}, \bar{\delta}_{\mathrm{j}}\right) \equiv \mathrm{q}_{2}\left[1-\mathrm{H}\left(\bar{\delta}_{\mathrm{j}}\right)\right]\left[\mathrm{L}_{2} \delta_{\mathrm{i}}-\mathrm{c}_{2}-\mathrm{f}\right]+\left[1-\mathrm{q}_{2}+\mathrm{q}_{2} \mathrm{H}\left(\bar{\delta}_{\mathrm{j}}\right)\right]\left[\max \left\{0, \mathrm{z}^{\mathrm{N}}\left(\delta_{\mathrm{i}}, \bar{\delta}_{\mathrm{j}}\right)\right\}\right] \\
=\mathrm{q}_{2}\left[1-\mathrm{H}\left(\bar{\delta}_{\mathrm{j}}\right)\right]\left[\mathrm{L}_{2} \delta_{\mathrm{i}}-\mathrm{c}_{2}-\mathrm{f}\right]+\max \left\{0, \mathrm{q}_{2}\left[\mathrm{H}\left(\bar{\delta}_{\mathrm{j}}\right)-\mathrm{H}(\underline{\delta})\right]\left[\mathrm{L}_{2} \delta_{\mathrm{i}}-\mathrm{c}_{2}-\mathrm{f}\right]\right. \\
\left.+\left[1-\mathrm{q}_{2}+\mathrm{q}_{2} \mathrm{H}(\underline{\delta})\right]\left[\max \left\{\mathrm{L}_{1} \delta_{\mathrm{i}}-\mathrm{c}_{1}, 0\right\}-\mathrm{f}\right]\right\},
\end{gathered}
$$

where the expression max $\left\{0, \mathrm{q}_{2}\left[\mathrm{H}\left(\bar{\delta}_{\mathrm{j}}\right)-\mathrm{H}(\underline{\delta})\right]\left[\mathrm{L}_{2} \delta_{\mathrm{i}}-\mathrm{c}_{2}-\mathrm{f}\right]+\left[1-\mathrm{q}_{2}+\mathrm{q}_{2} \mathrm{H}(\underline{\delta})\right]\left[\max \left\{\mathrm{L}_{1} \delta_{\mathrm{i}}-\mathrm{c}_{1}, 0\right\}-\mathrm{f}\right]\right\}$ $(>,=) 0$ as $\delta_{i}(>, \leq) \psi\left(\bar{\delta}_{\mathrm{j}}\right)$. Victim i's expected payoff from filing suit in period 1 is unchanged from the two-period case, since filing in period 1 provokes any possible follow-on suits in period 2 :

$$
\mathrm{F}^{\mathrm{N}}\left(\delta_{\mathrm{i}}, \bar{\delta}_{\mathrm{j}}\right) \equiv \mathrm{q}_{2}[1-\mathrm{H}(\underline{\delta})]\left[\mathrm{L}_{2} \delta_{\mathrm{i}}-\mathrm{c}_{2}-\mathrm{f}\right]+\left[1-\mathrm{q}_{2}+\mathrm{q}_{2} \mathrm{H}(\underline{\delta})\right]\left[\max \left\{\mathrm{L}_{1} \delta_{\mathrm{i}}-\mathrm{c}_{1}, 0\right\}-\mathrm{f}\right] .
$$

Let $\mathcal{Z}^{\mathrm{N}}\left(\delta_{\mathrm{i}}, \bar{\delta}_{\mathrm{j}}\right) \equiv \mathrm{F}^{\mathrm{N}}\left(\delta_{\mathrm{i}}, \bar{\delta}_{\mathrm{j}}\right)-\psi^{\mathrm{N}}\left(\delta_{\mathrm{i}}, \bar{\delta}_{\mathrm{j}}\right)$ denote the net value of filing in period 1 (net of the value of waiting and then behaving optimally in all future periods). Then

$$
\begin{aligned}
& \mathcal{Z}^{\mathrm{N}}\left(\delta_{\mathrm{i}}, \bar{\delta}_{\mathrm{j}}\right)=\mathrm{q}_{2}\left[\mathrm{H}\left(\bar{\delta}_{\mathrm{j}}\right)-\mathrm{H}(\underline{\delta})\right]\left[\mathrm{L}_{2} \delta_{\mathrm{i}}-\mathrm{c}_{2}-\mathrm{f}\right]+\left[1-\mathrm{q}_{2}+\mathrm{q}_{2} \mathrm{H}(\underline{\delta})\right]\left[\max \left\{\mathrm{L}_{1} \delta_{\mathrm{i}}-\mathrm{c}_{1}, 0\right\}-\mathrm{f}\right] \\
& -\max \left\{0, \mathrm{q}_{2}\left[\mathrm{H}\left(\bar{\delta}_{\mathrm{j}}\right)-\mathrm{H}(\underline{\delta})\right]\left[\mathrm{L}_{2} \delta_{\mathrm{i}}-\mathrm{c}_{2}-\mathrm{f}\right]+\left[1-\mathrm{q}_{2}+\mathrm{q}_{2} \mathrm{H}(\underline{\delta})\right]\left[\max \left\{\mathrm{L}_{1} \delta_{\mathrm{i}}-\mathrm{c}_{1}, 0\right\}-\mathrm{f}\right]\right\} .
\end{aligned}
$$

We now characterize victim i's filing decision in period 1 , given victim j's bandwagon strategy $\bar{\delta}_{\text {j. }}$. As in the 2-period case, we will refer to the resulting threshold as $\varphi\left(\bar{\delta}_{\mathrm{j}}\right)$; we will use the same notation because, as we will see, the same equation determines $\varphi\left(\bar{\delta}_{\mathrm{j}}\right)$. First, consider $\bar{\delta}_{\mathrm{j}}=\underline{\delta}$; then $\mathcal{Z}^{\mathrm{N}}\left(\delta_{\mathrm{i}}, \underline{\delta}\right)=\left[1-\mathrm{q}_{2}+\mathrm{q}_{2} \mathrm{H}(\underline{\delta})\right]\left[\max \left\{\mathrm{L}_{1} \delta_{\mathrm{i}}-\mathrm{c}_{1}, 0\right\}-\mathrm{f}-\max \left\{0, \max \left\{\mathrm{L}_{1} \delta_{\mathrm{i}}-\mathrm{c}_{1}, 0\right\}-\mathrm{f}\right\}\right]$. Since $\mathcal{Z}^{\mathrm{N}}\left(\delta_{\mathrm{i}}, \underline{\delta}\right)$ $=0$ for $\delta_{\mathrm{i}} \geq \delta_{1}$ and $\mathcal{Z}^{\mathrm{N}}\left(\delta_{\mathrm{i}}, \underline{\delta}\right)<0$ for $\delta_{\mathrm{i}}<\delta_{1}$, it follows that $\varphi(\underline{\delta})=\delta_{1}$. Next, consider $\bar{\delta}_{\mathrm{j}}>\underline{\delta}$; then $\mathcal{Z}^{\mathrm{N}}\left(\underline{\delta}, \bar{\delta}_{\mathrm{j}}\right)=\left[1-\mathrm{q}_{2}+\mathrm{q}_{2} \mathrm{H}(\underline{\delta})\right]\left[\max \left\{\mathrm{L}_{1} \underline{\delta}-\mathrm{c}_{1}, 0\right\}-\mathrm{f}-\max \left\{0, \max \left\{\mathrm{L}_{1} \underline{\delta}-\mathrm{c}_{1}, 0\right\}-\mathrm{f}\right\}\right]<0$. Moreover, by the definition of $\psi\left(\bar{\delta}_{\mathrm{j}}\right)$, it follows that $\mathcal{Z}^{\mathrm{N}}\left(\delta_{\mathrm{i}}, \bar{\delta}_{\mathrm{j}}\right)=0$ for all $\delta_{\mathrm{i}} \geq \psi\left(\bar{\delta}_{\mathrm{j}}\right)$. Finally, for $\delta_{\mathrm{i}} \in\left(\underline{\delta}, \psi\left(\bar{\delta}_{\mathrm{j}}\right)\right)$, the function $\mathcal{Z}^{\mathrm{N}}\left(\delta_{\mathrm{i}}, \bar{\delta}_{\mathrm{j}}\right)=\mathrm{q}_{2}\left[\mathrm{H}\left(\bar{\delta}_{\mathrm{j}}\right)-\mathrm{H}(\underline{\delta})\right]\left[\mathrm{L}_{2} \delta_{\mathrm{i}}-\mathrm{c}_{2}-\mathrm{f}\right]+\left[1-\mathrm{q}_{2}+\mathrm{q}_{2} \mathrm{H}(\underline{\delta})\right]\left[\max \left\{\mathrm{L}_{1} \delta_{\mathrm{i}}-\mathrm{c}_{1}, 0\right\}\right.$ - f $]$ is strictly increasing in $\delta_{\mathrm{i}}$. These facts jointly imply that a victim with $\delta_{\mathrm{i}} \geq \psi\left(\bar{\delta}_{\mathrm{j}}\right)$ is indifferent about filing in period 1 or waiting and, by our assumption that victims file when indifferent, these victims file in period 1. Thus, the first-period filing threshold $\varphi\left(\bar{\delta}_{\mathrm{j}}\right)$ is equal to $\psi\left(\bar{\delta}_{\mathrm{j}}\right)$. A victim with $\delta_{\mathrm{i}} \in\left[\underline{\hat{\delta}}, \varphi\left(\bar{\delta}_{\mathrm{j}}\right)\right)$ will wait in period 1 and file in period 2 only if another victim $\mathrm{j}$ is available to be joined. No filings will occur (along the equilibrium path) in period 2 following a history of no filings in period 1 because any type that would be willing to do so will have already filed in period 1 . Finally, we 
simply note that the equation defining $\varphi\left(\bar{\delta}_{\mathrm{j}}\right)$ is the same in the two-period case (wherein the expression in equation (5) is set equal to zero to obtain $\varphi\left(\bar{\delta}_{\mathrm{j}}\right)$ ) and in the multi-period case (wherein the expression in equation (A1) is set equal to zero to obtain $\psi\left(\bar{\delta}_{\mathrm{j}}\right)$, which is equal to $\left.\varphi\left(\bar{\delta}_{\mathrm{j}}\right)\right)$. Since we know that the same equation defines $\varphi\left(\bar{\delta}_{\mathrm{j}}\right)$, the remainder of the argument from the two-period case establishes the existence of a unique symmetric bandwagon equilibrium for the multi-period case, and it is the same bandwagon equilibrium as in the two-period case: $\left\{\underline{\delta}, \bar{\delta}^{\mathrm{N}}\right\}$.

\section{Equilibrium Dynamics when Some Victims are Unaware of the Source of Harm}

Suppose no settlement is possible. By waiting in period 1 , an aware victim i expects to receive a payoff of:

$\mathrm{W}_{\rho}^{\mathrm{N}}\left(\delta_{\mathrm{i}}, \bar{\delta}_{\mathrm{j}}\right) \equiv \rho \mathrm{q}_{2}\left[1-\mathrm{H}\left(\bar{\delta}_{\mathrm{j}}\right)\right]\left[\mathrm{L}_{2} \delta_{\mathrm{i}}-\mathrm{c}_{2}-\mathrm{f}\right]+\left[1-\mathrm{q}_{2}+(1-\rho) \mathrm{q}_{2}+\rho \mathrm{q}_{2} \mathrm{H}\left(\bar{\delta}_{\mathrm{j}}\right)\right]\left[\max \left\{\mathrm{L}_{1} \delta_{\mathrm{i}}-\mathrm{c}_{1}-\mathrm{f}, 0\right\}\right]$.

The reasoning is as follows. If victim $\mathrm{i}$ waits in period 1 , then with probability $\rho \mathrm{q}_{2}\left[1-\mathrm{H}\left(\bar{\delta}_{\mathrm{j}}\right)\right]$ victim $\mathrm{j}$ exists, is aware, and has damages sufficient to induce her to file suit in period 1 (and hence will be available for victim $i$ to join in period 2$)$. On the other hand, with probability $\left[1-q_{2}+(1-\rho) q_{2}+\right.$ $\left.\rho q_{2} \mathrm{H}\left(\bar{\delta}_{\mathrm{j}}\right)\right]$ victim $\mathrm{j}$ does not exist, or exists but is unaware, or exists and is aware but does not have damages sufficient to induce her to file suit in period 1; in all of these cases, victim $i$ will be left to file alone in period 2 .

Now suppose that victim i files suit in period 1. Then he expects to receive a payoff of:

$$
\begin{gathered}
\mathrm{F}_{\rho}^{\mathrm{N}}\left(\delta_{\mathrm{i}}, \bar{\delta}_{\mathrm{j}}\right) \equiv \rho \mathrm{q}_{2}\left[1-\mathrm{H}\left(\bar{\delta}_{\mathrm{j}}\right)\right]\left[\mathrm{L}_{2} \delta_{\mathrm{i}}-\mathrm{c}_{2}-\mathrm{f}\right]+\left\{(1-\rho) \mathrm{q}_{2}\left[1-\mathrm{H}\left(\bar{\delta}_{\mathrm{j}}\right)\right]+\mathrm{q}_{2}\left[\mathrm{H}\left(\bar{\delta}_{\mathrm{j}}\right)-\mathrm{H}(\underline{\delta})\right]\right\}\left[\mathrm{L}_{2} \delta_{\mathrm{i}}-\mathrm{c}_{2}-\mathrm{f}\right] \\
+\left[1-\mathrm{q}_{2}+\mathrm{q}_{2} \mathrm{H}(\underline{\delta})\right]\left[\max \left\{\mathrm{L}_{1} \delta_{\mathrm{i}}-\mathrm{c}_{1}, 0\right\}-\mathrm{f}\right] .
\end{gathered}
$$

To see why, notice that if victim i files in period 1 , then regardless of what else happens he will pay the fee $\mathrm{f}$. If victim $\mathrm{j}$ exists and is aware (this occurs with probability $\rho q_{2}$ ), then she will also file in period 1 if $\delta_{\mathrm{j}} \geq \bar{\delta}_{\mathrm{j}}$. If victim $\mathrm{j}$ exists, is unaware, and has $\delta_{\mathrm{j}} \geq \bar{\delta}_{\mathrm{j}}$, or if she exists and has $\underline{\delta} \leq \delta_{\mathrm{j}}<\bar{\delta}_{\mathrm{j}}$, then she will wait in period 1, but she will become aware (as a consequence of $\mathrm{P}_{\mathrm{i}}$ 's filing suit) and thus she will file subsequently in period 2 (and join $P_{i}$ ). Finally, if victim $j$ does not exist, or she does exist but has damages less than $\underline{\delta}$, then victim $j$ will never file. In this case, victim $i$ will decide between dropping his case and receiving 0 or continuing and receiving $\mathrm{L}_{1} \delta_{\mathrm{i}}-\mathrm{c}_{1}$. Upon collecting terms, we note that $\mathrm{F}_{\rho}^{\mathrm{N}}\left(\delta_{\mathrm{i}}, \bar{\delta}_{\mathrm{j}}\right)$ is the same as $\mathrm{F}^{\mathrm{N}}\left(\delta_{\mathrm{i}}, \bar{\delta}_{\mathrm{j}}\right)$ for all $\rho$; the value of filing suit (for an aware victim) is independent of the likelihood that the other victim is aware.

$$
\mathrm{F}_{\rho}^{\mathrm{N}}\left(\delta_{\mathrm{i}}, \bar{\delta}_{\mathrm{j}}\right) \equiv \mathrm{q}_{2}[1-\mathrm{H}(\underline{\delta})]\left[\mathrm{L}_{2} \delta_{\mathrm{i}}-\mathrm{c}_{2}-\mathrm{f}\right]+\left[1-\mathrm{q}_{2}+\mathrm{q}_{2} \mathrm{H}(\underline{\delta})\right]\left[\max \left\{\mathrm{L}_{1} \delta_{\mathrm{i}}-\mathrm{c}_{1}, 0\right\}-\mathrm{f}\right] .
$$

Let $\mathrm{Z}_{\rho}^{\mathrm{N}}\left(\delta_{\mathrm{i}}, \bar{\delta}_{\mathrm{j}}\right) \equiv \mathrm{F}_{\rho}^{\mathrm{N}}\left(\delta_{\mathrm{i}}, \bar{\delta}_{\mathrm{j}}\right)-\mathrm{W}_{\rho}^{\mathrm{N}}\left(\delta_{\mathrm{i}}, \bar{\delta}_{\mathrm{j}}\right)$ denote the net value of filing in period 1 (net of the value of waiting and then behaving optimally in period 2), for $\rho \in(0,1)$. Then (by arguments analogous to the case of $\rho=1)$, the symmetric bandwagon equilibrium period 1 filing threshold is given by $\bar{\delta}_{\rho}^{\mathrm{N}}$ $\in\left(\underline{\delta}, \delta_{1}\right)$ such that $\mathrm{Z}_{\rho}^{\mathrm{N}}\left(\bar{\delta}_{\rho}^{\mathrm{N}}, \bar{\delta}_{\rho}^{\mathrm{N}}\right)=0$. Since $\mathrm{F}_{\rho}^{\mathrm{N}}(\delta, \delta)$ is independent of $\rho$ and $\mathrm{W}_{\rho}^{\mathrm{N}}(\delta, \delta)$ is increasing in $\rho$, it follows that $\bar{\delta}_{\rho}^{\mathrm{N}}$ is an increasing function of $\rho$ which converges to $\bar{\delta}^{\mathrm{N}}$ as $\rho \rightarrow 1$. Moreover, since $\mathrm{F}_{\rho}^{\mathrm{N}}\left(\delta_{\mathrm{i}}, \bar{\delta}_{\mathrm{j}}\right)=\mathrm{F}^{\mathrm{N}}\left(\delta_{\mathrm{i}}, \bar{\delta}_{\mathrm{j}}\right)=\mathrm{F}^{\mathrm{S}}\left(\delta_{\mathrm{i}}, \bar{\delta}_{\mathrm{j}}\right)$ (that is, when $\rho=1$ the value of filing in period 1 is the same when 
early settlements are allowed as when they are not allowed, see equations (2) and (7) in the main text), it follows that $\bar{\delta}_{\rho}^{\mathrm{N}}$ converges to $\bar{\delta}^{\mathrm{S}}$ as $\rho \rightarrow 0$.

Now suppose that, at every stage, D can offer a settlement to any plaintiff who has filed suit; we assume that settlement negotiation occurs at the "end" of each period. Suppose $\mathrm{P}_{\mathrm{i}}$ learns that he filed alone in period 1; he uses this observation to update his beliefs about $\mathrm{P}_{\mathrm{j}}$. This event occurs if either (1) there is no victim $\mathrm{j}$; or (2) there is a victim $\mathrm{j}$ but she is unaware; or (3) there is a victim $\mathrm{j}$ and she is aware, but she has damages $\delta_{\mathrm{j}}<\bar{\delta}_{\mathrm{j}}$. These events have combined probability $\left[1-\mathrm{q}_{2}+\mathrm{q}_{2}(1\right.$ $\left.-\rho)+\rho q_{2} \mathrm{H}\left(\bar{\delta}_{\mathrm{j}}\right)\right]$. Thus, upon learning that he filed alone in period $1, \mathrm{P}_{\mathrm{i}}$ anticipates that he will be joined by $\mathrm{P}_{\mathrm{j}}$ in period 2 with probability $\left[\mathrm{q}_{2}(1-\rho)\left[1-\mathrm{H}\left(\bar{\delta}_{\mathrm{j}}\right)\right]+\mathrm{q}_{2}\left[\mathrm{H}\left(\bar{\delta}_{\mathrm{j}}\right)-\mathrm{H}(\underline{\delta})\right]\right] /\left[1-\mathrm{q}_{2}+\mathrm{q}_{2}(1-\rho)\right.$ $\left.+\rho q_{2} \mathrm{H}\left(\bar{\delta}_{\mathrm{j}}\right)\right]$ and will ultimately receive a settlement of $\mathrm{S}_{2}^{2}\left(\delta_{\mathrm{i}}\right) \equiv \mathrm{L}_{2} \delta_{\mathrm{i}}-\mathrm{c}_{2}$. On the other hand, $\mathrm{P}_{\mathrm{i}}$ anticipates that he will not be joined by a $\mathrm{P}_{\mathrm{j}}$ in period 2 with probability $\left[1-\mathrm{q}_{2}+\mathrm{q}_{2} \mathrm{H}(\underline{\delta})\right] /\left[1-\mathrm{q}_{2}+\right.$ $\left.\mathrm{q}_{2}(1-\rho)+\rho \mathrm{q}_{2} \mathrm{H}\left(\bar{\delta}_{\mathrm{j}}\right)\right]$, and will ultimately receive a settlement of $\mathrm{s}_{1}^{2}\left(\delta_{\mathrm{i}}\right) \equiv \max \left\{\mathrm{L}_{1} \delta_{\mathrm{i}}-\mathrm{c}_{1}, 0\right\}$. Combining these gives $\mathrm{P}_{\mathrm{i}}$ 's expected continuation value if he filed alone in period 1; by assumption, this is what $\mathrm{D}$ must offer to induce $\mathrm{P}_{\mathrm{i}}$ to settle. Since this will depend on the bandwagon strategy being played by $\mathrm{P}_{\mathrm{j}}$ (which is taken as given by both $\mathrm{P}_{\mathrm{i}}$ and $\mathrm{D}$ ), we denote this amount by $\mathrm{S}_{1 \rho}^{1}\left(\delta_{\mathrm{i}}, \bar{\delta}_{\mathrm{j}}\right.$ ).

$$
\begin{gathered}
\mathrm{s}_{1 \rho}^{1}\left(\delta_{\mathrm{i}}, \bar{\delta}_{\mathrm{j}}\right) \equiv\{[ \\
\left.\left[\mathrm{q}_{2}(1-\rho)\left[1-\mathrm{H}\left(\bar{\delta}_{\mathrm{j}}\right)\right]+\mathrm{q}_{2}\left[\mathrm{H}\left(\bar{\delta}_{\mathrm{j}}\right)-\mathrm{H}(\underline{\delta})\right]\right] /\left[1-\mathrm{q}_{2}+\mathrm{q}_{2}(1-\rho)+\rho \mathrm{q}_{2} \mathrm{H}\left(\bar{\delta}_{\mathrm{j}}\right)\right]\right\}\left[\mathrm{L}_{2} \delta_{\mathrm{i}}-\mathrm{c}_{2}\right] \\
+\left\{\left[1-\mathrm{q}_{2}+\mathrm{q}_{2} \mathrm{H}(\underline{\delta})\right] /\left[1-\mathrm{q}_{2}+\mathrm{q}_{2}(1-\rho)+\rho \mathrm{q}_{2} \mathrm{H}\left(\bar{\delta}_{\mathrm{j}}\right)\right]\right\}\left[\max \left\{\mathrm{L}_{1} \delta_{\mathrm{i}}-\mathrm{c}_{1}, 0\right\}\right] .
\end{gathered}
$$

Now consider $\mathrm{P}_{\mathrm{i}}$ 's optimal decision in period 1. As before, if $\mathrm{P}_{\mathrm{i}}$ waits in period 1 , he does not expect to be able to join another plaintiff in period 2; either $\mathrm{P}_{\mathrm{j}}$ does not exist, or she exists, but did not file suit (either because she is unaware or she was waiting to follow $\mathrm{P}_{\mathrm{i}}$ and will not file in period 2 since $\mathrm{P}_{\mathrm{i}}$ did not file in period 1), or she exists and she did file suit in period 1, but settled her suit. Thus, if $\mathrm{P}_{\mathrm{i}}$ waits in period 1 , then he will file suit in period 2 only if $\delta_{i} \geq \delta_{1}$. That is, $\mathrm{P}_{\mathrm{i}}$ 's expected payoff from waiting in period 1 is:

$$
\mathrm{W}_{\rho}^{\mathrm{S}}\left(\delta_{\mathrm{i}}, \bar{\delta}_{\mathrm{j}}\right)=\max \left\{\mathrm{L}_{1} \delta_{\mathrm{i}}-\mathrm{c}_{1}-\mathrm{f}, 0\right\}
$$

On the other hand, $\mathrm{P}_{\mathrm{i}}$ 's expected payoff if he files in period 1 is:

$$
\begin{aligned}
\mathrm{F}_{\rho}^{\mathrm{S}}\left(\delta_{\mathrm{i}}, \bar{\delta}_{\mathrm{j}}\right)=\rho \mathrm{q}_{2}\left[1-\mathrm{H}\left(\bar{\delta}_{\mathrm{j}}\right)\right]\left[\mathrm{L}_{2} \delta_{\mathrm{i}}-\mathrm{c}_{2}-\mathrm{f}\right]+\left[1-\mathrm{q}_{2}+\mathrm{q}_{2}(1-\rho)+\rho \mathrm{q}_{2} \mathrm{H}\left(\bar{\delta}_{\mathrm{j}}\right)\right]\left[\mathrm{s}_{1}^{1}\left(\delta_{\mathrm{i}}, \bar{\delta}_{\mathrm{j}}\right)-\mathrm{f}\right] \\
=\mathrm{q}_{2}[1-\mathrm{H}(\underline{\delta})]\left[\mathrm{L}_{2} \delta_{\mathrm{i}}-\mathrm{c}_{2}-\mathrm{f}\right]+\left[1-\mathrm{q}_{2}+\mathrm{q}_{2} \mathrm{H}(\underline{\delta})\right]\left[\max \left\{\mathrm{L}_{1} \delta_{\mathrm{i}}-\mathrm{c}_{1}, 0\right\}-\mathrm{f}\right] .
\end{aligned}
$$

Note that $\mathrm{F}_{\rho}^{\mathrm{S}}\left(\delta_{\mathrm{i}}, \bar{\delta}_{\mathrm{j}}\right)$ is exactly the same as $\mathrm{F}^{\mathrm{S}}\left(\delta_{\mathrm{i}}, \bar{\delta}_{\mathrm{j}}\right)\left(\right.$ and $\mathrm{F}_{\rho}^{\mathrm{N}}\left(\delta_{\mathrm{i}}, \bar{\delta}_{\mathrm{j}}\right)$ and $\left.\mathrm{F}^{\mathrm{N}}\left(\delta_{\mathrm{i}}, \bar{\delta}_{\mathrm{j}}\right)\right)$. The value of filing in period 1 is independent of $\rho$ and is the same whether or not settlement is deferred. All of these expressions are equal because of the assumption that $\mathrm{D}$ needs only to offer $\mathrm{P}_{\mathrm{i}}$ 's continuation value in settlement. Since $\mathrm{F}_{\rho}^{\mathrm{S}}\left(\delta_{\mathrm{i}}, \bar{\delta}_{\mathrm{j}}\right)$ and $\mathrm{W}_{\rho}^{\mathrm{S}}\left(\delta_{\mathrm{i}}, \bar{\delta}_{\mathrm{j}}\right)$ are independent of $\rho$, their difference $\mathrm{Z}_{\rho}^{\mathrm{S}}\left(\delta_{\mathrm{i}}, \bar{\delta}_{\mathrm{j}}\right) \equiv$ $\mathrm{F}_{\rho}^{\mathrm{S}}\left(\delta_{\mathrm{i}}, \bar{\delta}_{\mathrm{j}}\right)-\mathrm{W}_{\rho}^{\mathrm{S}}\left(\delta_{\mathrm{i}}, \bar{\delta}_{\mathrm{j}}\right)$ is also independent of $\rho$, as is the solution $\bar{\delta}_{\rho}^{\mathrm{S}}$ to the equation $Z_{\rho}^{\mathrm{S}}(\delta, \delta)=0$. That is, when settlement is possible at every stage, the period 1filing threshold is $\bar{\delta}_{\rho}^{\mathrm{S}}=\bar{\delta}^{\mathrm{S}}$ for all $\rho$. 


\section{Technical Appendix}

"A Dynamic Model of Lawsuit Joinder and Settlement"

A. Daughety and J. Reinganum

July 2009

\section{Derivation of $f_{N Q}$}

To find an implicit condition so that $\bar{\delta}^{\mathrm{N}}<\delta_{\mathrm{Q}}$, first observe that if $\delta_{\mathrm{Q}} \leq \underline{\delta}$, then it is immediate that $\bar{\delta}^{\mathrm{N}}>\delta_{\mathrm{Q}}$ since $\bar{\delta}^{\mathrm{N}}>\underline{\delta}$. A sufficient condition for this to occur is if $\delta_{\mathrm{Q}}=\mathrm{c}_{1} / \mathrm{L}_{1} \leq\left(\mathrm{c}_{2}+\mathrm{f}\right) / \mathrm{L}_{2}=\underline{\delta}$; that is, if $\mathrm{f} \geq \mathrm{f}^{\max } \equiv\left(\mathrm{c}_{1} \mathrm{~L}_{2}-\mathrm{c}_{2} \mathrm{~L}_{1}\right) / \mathrm{L}_{1}$. In this case, while all types $\delta_{\mathrm{i}} \in\left[\bar{\delta}^{\mathrm{N}}, \delta_{1}\right)$ regret having paid the fixed cost $\mathrm{f}$, none would drop, as the expected value to continuing alone is non-negative. Clearly this is a overly strong requirement on $\mathrm{f}$ such that no cases, once filed, are dropped. To find a necessary condition, consider $\mathrm{f} \in\left(0, \mathrm{f}^{\text {max }}\right)$, so that $\delta_{Q}>\underline{\delta}$, and evaluate

$$
\mathrm{Z}^{\mathrm{N}}(\delta, \delta ; \mathrm{f}) \equiv \mathrm{q}_{2}[\mathrm{H}(\delta)-\mathrm{H}(\underline{\delta})]\left[\mathrm{L}_{2} \delta-\mathrm{c}_{2}-\mathrm{f}\right]+\left[1-\mathrm{q}_{2}+\mathrm{q}_{2} \mathrm{H}(\underline{\delta})\right]\left[\max \left\{\mathrm{L}_{1} \delta-\mathrm{c}_{1}, 0\right\}-\mathrm{f}\right]
$$

at $\delta=\delta_{\mathrm{Q}}$, where we have included the fee $\mathrm{f}$ as a parameter in $\mathrm{Z}^{\mathrm{N}}$ (and recall that $\underline{\delta}=\left(\mathrm{c}_{2}+\mathrm{f}\right) / \mathrm{L}_{2}$ ).

Then $\mathrm{Z}^{\mathrm{N}}\left(\delta_{\mathrm{Q}}, \delta_{\mathrm{Q}} ; \mathrm{f}\right)=\mathrm{q}_{2}\left[\mathrm{H}\left(\delta_{\mathrm{Q}}\right)-\mathrm{H}(\underline{\delta})\right]\left[\mathrm{L}_{2} \delta_{\mathrm{Q}}-\mathrm{c}_{2}\right]-\left[1-\mathrm{q}_{2}+\mathrm{q}_{2} \mathrm{H}(\underline{\delta})\right]$ f. Since $\mathrm{Z}^{\mathrm{N}}$ is strictly increasing in both arguments involving $\delta_{\mathrm{Q}}$, and since $Z^{\mathrm{N}}\left(\bar{\delta}^{\mathrm{N}}, \bar{\delta}^{\mathrm{N}} ; \mathrm{f}\right)=0$, it is clear that $\bar{\delta}^{\mathrm{N}}(>,=,<) \delta_{\mathrm{Q}}$ as $Z^{\mathrm{N}}\left(\delta_{\mathrm{Q}}, \delta_{\mathrm{Q}} ; \mathrm{f}\right)(<,=,>) 0$. As $\mathrm{f} \rightarrow 0, \bar{\delta}^{\mathrm{N}} \rightarrow \underline{\delta}<\delta_{\mathrm{Q}}$, where the inequality follows from the fact that $\delta_{\mathrm{Q}}=\mathrm{c}_{1} / \mathrm{L}_{1}>\mathrm{c}_{2} / \mathrm{L}_{2}$. Thus, for $\mathrm{f}$ sufficiently low, we have $\mathrm{Z}^{\mathrm{N}}\left(\delta_{\mathrm{Q}}, \delta_{\mathrm{Q}} ; \mathrm{f}\right)>0$ and therefore $\bar{\delta}^{\mathrm{N}}<\delta_{\mathrm{Q}}$. Moreover, $\partial \mathrm{Z}^{\mathrm{N}}(\delta, \delta ; \mathrm{f}) / \partial \mathrm{f}=-\mathrm{q}_{2} \mathrm{~h}(\underline{\delta})\left[\mathrm{L}_{2} \delta-\mathrm{c}_{2}\right] / \mathrm{L}_{2}-\left[1-\mathrm{q}_{2}+\mathrm{q}_{2} \mathrm{H}(\underline{\delta})\right]<0$ for all $\delta \geq \underline{\delta}$. Therefore, there exists a unique value of $\mathrm{f} \in\left(0, \mathrm{f}^{\text {max }}\right)$, denoted $\mathrm{f}_{\mathrm{NQ}}$, such that $\bar{\delta}^{\mathrm{N}}(>,=,<) \delta_{\mathrm{Q}}$ as $\mathrm{f}(>,=,<) \mathrm{f}_{\mathrm{NQ}}$.

\section{Comparative Statics}

Recall that $\underline{\delta} \equiv\left(c_{2}+\mathrm{f}\right)$ and $\bar{\delta}^{\mathrm{N}}$ is defined by the following equation:

$$
\mathrm{Z}^{\mathrm{N}}\left(\bar{\delta}^{\mathrm{N}}, \bar{\delta}^{\mathrm{N}}\right)=\mathrm{q}_{2}\left[\mathrm{H}\left(\bar{\delta}^{\mathrm{N}}\right)-\mathrm{H}(\underline{\delta})\right]\left[\mathrm{L}_{2} \bar{\delta}^{\mathrm{N}}-\mathrm{c}_{2}-\mathrm{f}\right]+\left[1-\mathrm{q}_{2}+\mathrm{q}_{2} \mathrm{H}(\underline{\delta})\right]\left[\max \left\{\mathrm{L}_{1} \bar{\delta}^{\mathrm{N}}-\mathrm{c}_{1}, 0\right\}-\mathrm{f}\right]=0 .
$$

This means that $\mathrm{L}_{2} \bar{\delta}^{\mathrm{N}}-\mathrm{c}_{2}-\mathrm{f}>0$ and $\max \left\{\mathrm{L}_{1} \bar{\delta}^{\mathrm{N}}-\mathrm{c}_{1}, 0\right\}-\mathrm{f}<0$. The comparative statics of $\underline{\delta}$ with respect to the parameters $\mathrm{f}, \mathrm{c}_{2}, \mathrm{~L}_{2}$, and $\mathrm{q}_{2}$ are obvious. Recall that the function $\mathrm{Z}^{\mathrm{N}}\left(\bar{\delta}^{\mathrm{N}}, \bar{\delta}^{\mathrm{N}}\right)$ is strictly increasing in $\bar{\delta}^{\mathrm{N}}$ and depends on the parameters $\mathrm{f}, \mathrm{c}_{2}, \mathrm{~L}_{2}$, and $\mathrm{q}_{2}$ both directly and (possibly) indirectly through $\underline{\delta}$. Thus, for any parameter $\mathrm{m}$,

$$
\mathrm{d} \bar{\delta}^{\mathrm{N}} / \mathrm{dm}=-\left(\partial \mathrm{Z}^{\mathrm{N}}\left(\bar{\delta}^{\mathrm{N}}, \bar{\delta}^{\mathrm{N}}\right) / \partial \mathrm{m}\right) /\left[\mathrm{Z}_{1}^{\mathrm{N}}\left(\bar{\delta}^{\mathrm{N}}, \bar{\delta}^{\mathrm{N}}\right)+\mathrm{Z}_{1}^{\mathrm{N}}\left(\bar{\delta}^{\mathrm{N}}, \bar{\delta}^{\mathrm{N}}\right)\right],
$$

so that $\bar{\delta}^{\mathrm{N}}$ is an increasing function of any parameter $m$ which decreases $Z^{\mathrm{N}}\left(\bar{\delta}^{\mathrm{N}}, \bar{\delta}^{\mathrm{N}}\right)$, taking into account any indirect effects through $\underline{\delta}$. It is shown below that $\partial \mathrm{Z}^{\mathrm{N}}\left(\bar{\delta}^{\mathrm{N}}, \bar{\delta}^{\mathrm{N}}\right) / \partial \mathrm{f}<0$ and $\partial \mathrm{Z}^{\mathrm{N}}\left(\bar{\delta}^{\mathrm{N}}, \bar{\delta}^{\mathrm{N}}\right) / \partial \mathrm{c}_{2}$ $<0$, so the period 1 filing threshold increases (fewer cases are filed in period 1 ) with an increase in $\mathrm{f}$ or $\mathrm{c}_{2}$. On the other hand, $\partial \mathrm{Z}^{\mathrm{N}}\left(\bar{\delta}^{\mathrm{N}}, \bar{\delta}^{\mathrm{N}}\right) / \partial \mathrm{L}_{2}>0$ and $\partial \mathrm{Z}^{\mathrm{N}}\left(\bar{\delta}^{\mathrm{N}}, \bar{\delta}^{\mathrm{N}}\right) / \partial \mathrm{q}_{2}>0$, so the period 1 filing threshold decreases (more cases are filed in period 1) with an increase in $\mathrm{L}_{2}$.

$$
\begin{aligned}
& \partial \mathrm{Z}^{\mathrm{N}}\left(\bar{\delta}^{\mathrm{N}}, \bar{\delta}^{\mathrm{N}}\right) / \partial \mathrm{f}=-\left(\mathrm{\textrm {q } _ { 2 }} \mathrm{h}(\underline{\delta}) / \mathrm{L}_{2}\right)\left[\mathrm{L}_{2} \bar{\delta}^{\mathrm{N}}-\mathrm{c}_{2}-\max \left\{\mathrm{L}_{1} \bar{\delta}^{\mathrm{N}}-\mathrm{c}_{1}, 0\right\}\right]-\left[1-\mathrm{q}_{2}+\mathrm{q}_{2} \mathrm{H}\left(\bar{\delta}^{\mathrm{N}}\right)\right]<0 . \\
& \partial \mathrm{Z}^{\mathrm{N}}\left(\bar{\delta}^{\mathrm{N}}, \bar{\delta}^{\mathrm{N}}\right) / \partial \mathrm{c}_{2}=-\left(\mathrm{q}_{2} \mathrm{~h}(\underline{\delta}) / \mathrm{L}_{2}\right)\left[\mathrm{L}_{2} \bar{\delta}^{\mathrm{N}}-\mathrm{c}_{2}-\max \left\{\mathrm{L}_{1} \bar{\delta}^{\mathrm{N}}-\mathrm{c}_{1}, 0\right\}\right]-\mathrm{q}_{2}\left[\mathrm{H}\left(\bar{\delta}^{\mathrm{N}}\right)-\mathrm{H}(\underline{\delta})\right]<0 .
\end{aligned}
$$


$\partial \mathrm{Z}^{\mathrm{N}}\left(\bar{\delta}^{\mathrm{N}}, \bar{\delta}^{\mathrm{N}}\right) / \partial \mathrm{L}_{2}=\left[\mathrm{q}_{2} \mathrm{~h}(\underline{\delta})\left(\mathrm{c}_{2}+\mathrm{f}\right) /\left(\mathrm{L}_{2}\right)^{2}\right]\left[\mathrm{L}_{2} \bar{\delta}^{\mathrm{N}}-\mathrm{c}_{2}-\max \left\{\mathrm{L}_{1} \bar{\delta}^{\mathrm{N}}-\mathrm{c}_{1}, 0\right\}\right]+\mathrm{q}_{2}\left[\mathrm{H}\left(\bar{\delta}^{\mathrm{N}}\right)-\mathrm{H}(\underline{\delta})\right] \bar{\delta}^{\mathrm{N}}>0$.

$\partial \mathrm{Z}^{\mathrm{N}}\left(\bar{\delta}^{\mathrm{N}}, \bar{\delta}^{\mathrm{N}}\right) / \partial \mathrm{q}_{2}=\left[\mathrm{H}\left(\bar{\delta}^{\mathrm{N}}\right)-\mathrm{H}(\underline{\delta})\right]\left[\mathrm{L}_{2} \bar{\delta}^{\mathrm{N}}-\mathrm{c}_{2}-\mathrm{f}\right]-[1-\mathrm{H}(\underline{\delta})]\left[\max \left\{\mathrm{L}_{1} \bar{\delta}^{\mathrm{N}}-\mathrm{c}_{1}, 0\right\}-\mathrm{f}\right]>0$,

where the inequality follows from the facts that $\mathrm{L}_{2} \bar{\delta}^{\mathrm{N}}-\mathrm{c}_{2}-\mathrm{f}>0$ and $\max \left\{\mathrm{L}_{1} \bar{\delta}^{\mathrm{N}}-\mathrm{c}_{1}, 0\right\}-\mathrm{f}<0$.

Comparing the aggregate expected filing cost under preemptive versus deferred settlement

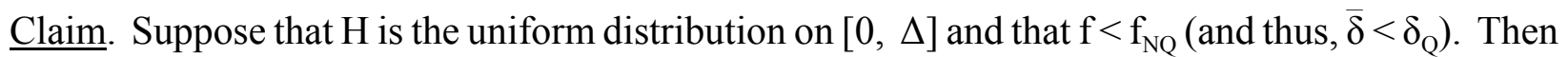
the expected filing cost for a single harmed plaintiff (which is proportional to the expected number of cases filed) is higher under preemptive settlement than under deferred settlement.

Proof. Let $\mathrm{EFC}^{*}$ denote the expected filing cost under deferred settlement and let $\mathrm{EFC}^{\mathrm{S} *}$ denote the expected filing cost under preemptive settlement. Then

$$
\mathrm{EFC}^{*}=\mathrm{f}\left[1-\mathrm{H}\left(\bar{\delta}^{\mathrm{N}}\right)\right]\left(1+\mathrm{q}_{2}\left[\mathrm{H}\left(\bar{\delta}^{\mathrm{N}}\right)-\mathrm{H}(\underline{\delta})\right]\right) \text { and } \mathrm{EFC}^{\mathrm{S} *}=\mathrm{f}\left[1-\mathrm{H}\left(\bar{\delta}^{\mathrm{S}}\right)\right]
$$

Using the uniform distribution:

$$
\operatorname{EFC}^{\mathrm{S} *}>\mathrm{EFC}^{*} \text { if and only if }\left(\Delta-\bar{\delta}^{\mathrm{S}}\right) / \Delta>\left[\left(\Delta-\bar{\delta}^{\mathrm{N}}\right) / \Delta\right]\left[1+\mathrm{q}_{2}\left(\bar{\delta}^{\mathrm{N}}-\underline{\delta}\right) / \Delta\right]
$$

(TA1) holds if and only if $\Delta\left(\Delta-\bar{\delta}^{\mathrm{S}}\right)>\left(\Delta-\bar{\delta}^{\mathrm{N}}\right)\left[\Delta+\bar{\delta}^{\mathrm{N}}-\underline{\delta}-\left(1-\mathrm{q}_{2}\right)\left(\bar{\delta}^{\mathrm{N}}-\underline{\delta}\right)\right]$, which holds if and only if

$$
\mathrm{q}_{2} \bar{\delta}^{\mathrm{N}}\left(\bar{\delta}^{\mathrm{N}}-\underline{\delta}\right)>\Delta\left[\bar{\delta}^{\mathrm{S}}-\underline{\delta}-\left(1-\mathrm{q}_{2}\right)\left(\bar{\delta}^{\mathrm{N}}-\underline{\delta}\right)\right]
$$

Using equations (5) and (8), the fact that $\bar{\delta}^{\mathrm{N}}<\delta_{\mathrm{Q}}$, and the uniform distribution yields the following relationship among the thresholds: $\bar{\delta}^{\mathrm{S}}-\underline{\delta}=\left(\bar{\delta}^{\mathrm{N}}-\underline{\delta}\right)^{2} /(\Delta-\underline{\delta})$. Substituting this into (TA2) implies that (TA2) holds if and only if $\mathrm{q}_{2} \bar{\delta}^{\mathrm{N}}\left(\bar{\delta}^{\mathrm{N}}-\underline{\delta}\right)>\Delta\left[\left(\left(\overline{\delta^{\mathrm{N}}}-\underline{\delta}\right)^{2} /(\Delta-\underline{\delta})\right)-\left(1-\mathrm{q}_{2}\right)\left(\bar{\delta}^{\mathrm{N}}-\underline{\delta}\right)\right]$, which holds if and only if $\mathrm{q}_{2} \bar{\delta}^{\mathrm{N}}(\Delta-\underline{\delta})>\Delta\left(\bar{\delta}^{\mathrm{N}}-\underline{\delta}\right)-\Delta\left(1-\mathrm{q}_{2}\right)(\Delta-\underline{\delta})$, which holds if and only if $\mathrm{q}_{2} \underline{\delta}+\left(1-\mathrm{q}_{2}\right) \Delta>0$, which is true. QED

\section{Preferences Over Preemptive versus Deferred Settlement in the Partially-Unaware Case}

It was claimed in the text that the plaintiff still prefers deferred to preemptive settlement, wile the defendant prefers to have the option to make a preemptive settlement when plaintiff awareness is sufficiently low. To demonstrate these claims, first consider the preferences of an aware harmed victim. Using notation analogous to that in the text, an aware harmed victim's expected equilibrium payoff under deferred and preemptive settlement, respectively, is given by:

$$
\mathrm{V}_{\rho}^{\mathrm{N}}\left(\delta_{\mathrm{i}}\right)= \begin{cases}0 & \delta_{\mathrm{i}} \in[0, \underline{\delta}) \\ \mathrm{W}_{\rho}^{\mathrm{N}}\left(\delta_{\mathrm{i}}, \bar{\delta}_{\rho}^{\mathrm{N}}\right) & \delta_{\mathrm{i}} \in\left[\underline{\bar{\delta}}, \bar{\delta}_{\rho}^{\mathrm{N}}\right) \\ \mathrm{F}_{\rho}^{\mathrm{N}}\left(\delta_{\mathrm{i}}, \bar{\delta}_{\rho}^{\mathrm{N}}\right) & \delta_{\mathrm{i}} \in\left[\bar{\delta}_{\rho}^{\mathrm{N}}, \infty\right)\end{cases}
$$


and

$$
\mathrm{V}_{\rho}^{\mathrm{S}}\left(\delta_{\mathrm{i}}\right)= \begin{cases}0 & \delta_{\mathrm{i}} \in\left[0, \bar{\delta}^{\mathrm{S}}\right) \\ \mathrm{F}_{\rho}^{\mathrm{S}}\left(\delta_{\mathrm{i}}, \bar{\delta}^{\mathrm{S}}\right) & \delta_{\mathrm{i}} \in\left[\bar{\delta}^{\mathrm{S}}, \infty\right) .\end{cases}
$$

In order to determine whether the plaintiff prefers deferred to preemptive settlement, we examine $\mathrm{V}_{\rho}^{\mathrm{N}}\left(\delta_{\mathrm{i}}\right)-\mathrm{V}_{\rho}^{\mathrm{S}}\left(\delta_{\mathrm{i}}\right)$. Since $\bar{\delta}^{\mathrm{S}}<\bar{\delta}_{\rho}^{\mathrm{N}}$ and $\mathrm{F}_{\rho}^{\mathrm{S}}\left(\delta_{\mathrm{i}}, \bar{\delta}^{\mathrm{S}}\right)=\mathrm{F}_{\rho}^{\mathrm{N}}\left(\delta_{\mathrm{i}}, \bar{\delta}_{\rho}^{\mathrm{N}}\right),{ }^{1}$ then the only places where $\mathrm{V}_{\rho}^{\mathrm{N}}\left(\delta_{\mathrm{i}}\right)$ differs from $\mathrm{V}_{\rho}^{\mathrm{S}}\left(\delta_{\mathrm{i}}\right)$ is on the two intervals $\left[\underline{\delta}, \bar{\delta}^{\mathrm{S}}\right)$ and $\left[\bar{\delta}^{\mathrm{S}}, \bar{\delta}_{\rho}^{\mathrm{N}}\right)$, since the two payoff functions are the same on the other intervals. Furthermore, $\mathrm{V}_{\rho}^{\mathrm{N}}\left(\delta_{\mathrm{i}}\right)-\mathrm{V}_{\rho}^{\mathrm{S}}\left(\delta_{\mathrm{i}}\right)=\mathrm{W}_{\rho}^{\mathrm{N}}\left(\delta_{\mathrm{i}}, \bar{\delta}_{\rho}^{\mathrm{N}}\right)-0>0$ on $\left[\underline{\delta}, \bar{\delta}^{\mathrm{S}}\right)$, while $\mathrm{V}_{\rho}^{\mathrm{N}}\left(\delta_{\mathrm{i}}\right)$ $\mathrm{V}_{\rho}^{\mathrm{S}}\left(\delta_{\mathrm{i}}\right)=\mathrm{W}_{\rho}^{\mathrm{N}}\left(\delta_{\mathrm{i}}, \bar{\delta}^{\mathrm{N}}\right)-\mathrm{F}_{\rho}^{\mathrm{N}}\left(\delta_{\mathrm{i}}, \bar{\delta}_{\rho}^{\mathrm{N}}\right)>0$ on $\left[\bar{\delta}^{\mathrm{S}}, \bar{\delta}_{\rho}^{\mathrm{N}}\right)$ since waiting is better than filing in the first period for these types. Thus, every type of aware harmed victim prefers deferred to preemptive settlement. It is clear that an unaware harmed victim prefers deferred to preemptive settlement, since deferred settlement involves a possibility that another victim may file suit and alert the unaware victim; by contrast, under preemptive settlement any (other) victim that files (early) ends up settling confidentially instead of alerting the unaware victim.

Now consider the ex ante preferences of the defendant. The defendant's expected payment is the ex ante expected number of harmed victims times the ex ante expected payment received by a harmed victim (this is tedious, but straightforward, to verify). We will now describe how to construct a harmed victim's expected receipts, taking into account that this victim may be aware or unaware. Under deferred settlement, a victim of type $\delta_{i}$ obtains the following payoffs:

(a) $\delta_{\mathrm{i}} \in[0, \underline{\delta}): \quad 0$

(b) $\delta_{i} \in\left[\underline{\delta}, \bar{\delta}_{\rho}^{\mathrm{N}}\right): \quad \rho \mathrm{q}_{2}\left[1-\mathrm{H}\left(\bar{\delta}_{\rho}^{\mathrm{N}}\right)\right]\left[\mathrm{L}_{2} \delta_{\mathrm{i}}-\mathrm{c}_{2}\right]$

(c) $\delta_{\mathrm{i}} \in\left[\bar{\delta}_{\rho}^{\mathrm{N}}, \infty\right): \quad \quad \quad \mathrm{q}_{2}[1-\mathrm{H}(\underline{\delta})]\left[\mathrm{L}_{2} \delta_{\mathrm{i}}-\mathrm{c}_{2}\right]+\rho\left[1-\mathrm{q}_{2}+\mathrm{q}_{2} \mathrm{H}(\underline{\delta})\right] \max \left\{\mathrm{L}_{1} \delta_{\mathrm{i}}-\mathrm{c}_{1}, 0\right\}$

$$
+(1-\rho) \rho q_{2}\left[1-H\left(\bar{\delta}_{\rho}^{N}\right)\right]\left[L_{2} \delta_{i}-c_{2}\right]
$$

These payoffs are explained as follows. A victim with $\delta_{i} \in[0, \underline{\delta})$ will never file suit, regardless of his level of awareness. A victim with $\delta_{i} \in\left[\underline{\delta}, \bar{\delta}_{\rho}^{N}\right)$ will wait in the first period, regardless of his level of awareness; consequently, he will file in period 2 if there is another victim, that victim is aware, and that victim has harm in excess of $\bar{\delta}_{\rho}^{\mathrm{N}}$; in this case, the other victim will file in period 1 and victim $i$ will join in period 2. Finally, a victim with $\delta_{i} \in\left[\bar{\delta}_{\rho}^{\mathrm{N}}, \infty\right)$ will file in period lif he is aware (this explains the first two expressions in part (c) above); if he is unaware, he will wait in period 1 but he will file in period 2 if there is another victim, that victim is aware, and that victim has harm in excess of $\bar{\delta}_{\rho}^{\mathrm{N}}$; this explains the third expression in part (c) above.

Under preemptive settlement, a victim of type $\delta_{\mathrm{i}}$ obtains the following payoffs (after substituting for the equilibrium settlement offer):

\footnotetext{
${ }^{1}$ Recall that $\mathrm{F}_{\rho}^{\mathrm{N}}$ and the reduced form of $\mathrm{F}_{\rho}^{\mathrm{S}}$ are both independent of the other potential victim's strategy.
} 
(d) $\delta_{\mathrm{i}} \in\left[0, \bar{\delta}^{\mathrm{S}}\right): \quad 0$

(e) $\delta_{\mathrm{i}} \in\left[\bar{\delta}^{\mathrm{s}}, \infty\right): \quad \quad \quad \mathrm{q}_{2}[1-\mathrm{H}(\underline{\delta})]\left[\mathrm{L}_{2} \delta_{\mathrm{i}}-\mathrm{c}_{2}\right]+\rho\left[1-\mathrm{q}_{2}+\mathrm{q}_{2} \mathrm{H}(\underline{\delta})\right] \max \left\{\mathrm{L}_{1} \delta_{\mathrm{i}}-\mathrm{c}_{1}, 0\right\}$

These payoffs are explained as follows. A victim with $\delta_{i} \in\left[0, \underline{\delta}^{S}\right)$ will not file suit in period 1, regardless of his level of awareness. Moreover, if there is another aware victim who files in period 1 , this plaintiff will settle with the defendant and will thus be unavailable to be joined in period 2 , and a victim with $\left[0, \bar{\delta}^{\mathrm{S}}\right.$ ) will not proceed alone. A victim with $\delta_{i} \in\left[\bar{\delta}^{\mathrm{S}}, \infty\right)$ will file in period 1 if he is aware; since this would permit him to alert any other victim, who would join in period 2 if her harm exceeds $\underline{\delta}$, victim i receives (via the settlement but gross of filing costs) the amount $\mathrm{q}_{2}[1$ $\mathrm{H}(\underline{\delta})]\left[\mathrm{L}_{2} \delta_{\mathrm{i}}-\mathrm{c}_{2}\right]+\left[1-\mathrm{q}_{2}+\mathrm{q}_{2} \mathrm{H}(\underline{\delta})\right] \max \left\{\mathrm{L}_{1} \delta_{\mathrm{i}}-\mathrm{c}_{1}, 0\right\}$ with probability $\rho$.

A harmed victim's expected receipts under deferred and preemptive settlement, respectively, are found by integrating the payoffs described in (a)-(c) and (d)-(e), respectively, with respect to the distribution $\mathrm{H}$. The defendant's ex ante expected payments are proportional to these expectations. The difference between the defendant's ex ante expected payments under deferred versus preemptive settlement are therefore proportional to $\rho \gamma(\rho)$, where

$$
\begin{array}{rlr}
\gamma(\rho) \equiv & \int \mathrm{q}_{2}\left[1-\mathrm{H}\left(\bar{\delta}_{\rho}^{\mathrm{N}}\right)\right]\left[\mathrm{L}_{2} \delta_{\mathrm{i}}-\mathrm{c}_{2}\right] \mathrm{h}\left(\delta_{\mathrm{i}}\right) \mathrm{d} \delta_{\mathrm{i}} & \text { (where the domain of integration is } \left.\left[\underline{\delta}, \bar{\delta}^{\mathrm{s}}\right]\right) \\
& \left.+\int(1-\rho) \mathrm{q}_{2}\left[1-\mathrm{H}\left(\bar{\delta}_{\rho}^{\mathrm{N}}\right)\right]\left[\mathrm{L}_{2} \delta_{\mathrm{i}}-\mathrm{c}_{2}\right] \mathrm{h}\left(\delta_{\mathrm{i}}\right) \mathrm{d} \delta_{\mathrm{i}} \quad \text { (where the domain of integration is }\left[\bar{\delta}_{\rho}^{\mathrm{N}}, \infty\right)\right) \\
& -\int\left\{\mathrm{q}_{2}\left[\mathrm{H}\left(\bar{\delta}_{\rho}^{\mathrm{N}}\right)-\mathrm{H}(\underline{\delta})\right]\left[\mathrm{L}_{2} \delta_{\mathrm{i}}-\mathrm{c}_{2}\right]+\left[1-\mathrm{q}_{2}+\mathrm{q}_{2} \mathrm{H}(\underline{\delta})\right] \max \left\{\mathrm{L}_{1} \delta_{\mathrm{i}}-\mathrm{c}_{1}, 0\right\}\right\} \mathrm{h}\left(\delta_{\mathrm{i}}\right) \mathrm{d} \delta_{\mathrm{i}},
\end{array}
$$

where the domain of integration for the final integral is $\left[\bar{\delta}^{\mathrm{S}}, \bar{\delta}_{\rho}^{\mathrm{N}}\right]$. Recall that $\partial \bar{\delta}_{\rho}^{\mathrm{N}} / \partial \rho>0$ and that $\bar{\delta}_{\rho}^{\mathrm{N}}$ $\rightarrow \bar{\delta}^{\mathrm{S}}$ as $\rho \rightarrow 0$. Totally differentiating $\gamma(\rho)$ with respect to $\rho$ implies that $\gamma(\rho)$ increases as $\rho$ decreases. Moreover, the first two integrals converge to positive numbers as $\rho \rightarrow 0$, while the third integral converges to zero. Thus, there is a value $\rho_{0}$ that is close enough to zero (but still positive) at which $\gamma\left(\rho_{0}\right)=0$; for any $\rho \in\left(0, \rho_{0}\right)$, it follows that $\rho \gamma(\rho)>0$. Thus, for sufficiently small levels of plaintiff awareness $\rho$, the defendant expects to pay more under deferred than under preemptive settlement. Thus, D prefers to have the option to make a preemptive settlement when plaintiff awareness is sufficiently low. 